\author{
Universidade de São Paulo \\ Faculdade de Medicina de Ribeirão Preto \\ Departamento de Fisiologia
}

GABRIELA SILVA BORGES

Efeito do citral no choque endotoxêmico

Ribeirão Preto 
GABRIELA SILVA BORGES

\section{Efeito do citral no choque endotoxêmico}

\section{Versão Original}

Dissertação apresentada ao Departamento de Fisiologia da Faculdade de Medicina de Ribeirão Preto, Universidade de São Paulo - FMRP/USP, para obtenção do título de Mestre em Ciências.

Área de concentração: Fisiologia

Orientador: Prof. Dr. Luiz Guilherme de Siqueira Branco

Ribeirão Preto 
Autorizo a reprodução e divulgação total ou parcial deste trabalho, por qualquer meio convencional ou eletrônico, para fins de estudo e pesquisa, desde que citada a fonte.

FICHA CATALOGRÁFICA

Borges, Gabriela Silva

Efeito do citral no choque endotoxêmico/Gabriela Silva Borges;

Orientador: Luiz Guilherme de Siqueira Branco - Ribeirão Preto, 2018.

56 p. : il. ; $30 \mathrm{~cm}$

Dissertação (Mestrado em Ciências - Área de concentração: Fisiologia) - Programa de Pós-Graduação em Fisiologia, Faculdade de Medicina de Ribeirão Preto, Universidade de São Paulo.

1.Choque séptico. 2. Termorregulação. 3. Citocinas inflamatórias. 4. Prostaglandinas. 5. Lipopolissacarídeo. 
BORGES, Gabriela Silva. Efeito do citral no choque endotoxêmico.

Dissertação apresentada à Faculdade de Medicina de Ribeirão Preto da Universidade de São Paulo, para obtenção do título de Mestre em Ciências. Área de concentração: Fisiologia.

Aprovada em:

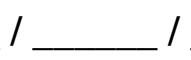

Banca Examinadora

Prof.(a) Dr. (a)

Instituição:

Julgamento: Assinatura:

Prof.(a) Dr. (a)

Instituição:

Julgamento:

Assinatura:

Prof.(a) Dr. (a)

Instituição:

Julgamento:

Assinatura:

Prof.(a) Dr. (a)

Instituição:

Julgamento:

Assinatura: 
"Minha mãe achava estudo a coisa mais fina do mundo.

Não é.

A coisa mais fina do mundo é o sentimento."

(PRADO, 1991) 


\section{DEDICATÓRIA}

Dedico essa dissertação e todo o esforço a ela empregado aos meus pais, Clarestina e Josimar.

Dedico também à Gabrielle Almeida Alves (in memoriam), uma moça doce, de olhinhos brilhantes e sorriso largo, que está na companhia de Deus, e em paz agora. Gabrielle não pôde concluir seu mestrado, e por isso a conclusão deste eu dedico à ela. Quanto mais claro o escuro se torna, com mais medo eu fico, mas mais coragem eu tenho para ir à luta. 


\section{AGRADECIMENTOS}

A Deus, pela companhia de todos os dias e por me me dar força e coragem.

À minha mãe, Clarestina, que doou seu tempo e esforço para dar suporte em todas as minhas empreitadas, e que mesmo com medo, sempre disse-me "vá", e ajudou-me a ir e ao meu pai, Josimar, que com determinação e trabalho árduo, junto de minha mãe, construiu a escada onde eu dei os primeiros passos rumo à construção de minha história. A ambos, agradeço pelo exemplo de esforço e pelo incentivo.

À minha irmã, Camila, por me incentivar a seguir em frente quando eu quis parar.

Ao meu noivo e colega de laboratório Eduardo, meu parceiro de todo momento, por me ajudar a escalar as pedras que encontrei pelo caminho.

Ao meu orientador, prof. Dr. Luiz Guilherme de Siqueira Branco, pela orientação. Agradeço por me aceitar para continuar o curso, pela confiança em minha capacidade e pelo acolhimento no laboratório. Ainda, pela humildade, alegria e carinho no tratamento com os alunos. Obrigada pelo exemplo, pela mão estendida e pelos sorrisos de bom dia.

Aos professores da graduação na UFU Drs. Marcos Luiz Ferreira Neto, Ana Paula Coelho Balbi, Luiz Borges Bispo e Patrícia Fidelis de Oliveira Gregolini, por acreditarem em mim, pelo exemplo profissional e por me mostrarem que a carreira científica pode ser bonita.

Ao meu colega de laboratório Maycon Emílio Tavares Silva pelo compartilhamento do projeto, sem o qual meu mestrado seria ainda mais desafiador.

À Bruna Maitan Santos, pelo tempo dispendido aos fins de semana e às noites no laboratório para a dosagem de prostaglandinas. Por me ensinar a coletar, preparar e seccionar os encéfalos, e pelas análises estatísticas.

Ao Mauro da Silva, técnico do laboratório, pela ajuda nos experimentos, sem a qual eu não conseguiria terminar em tempo hábil a coleta de dados.

À Clarissa Maria Dias Mota pela ajuda nas dosagens de interleucina e procedimentos envolvidos.

Ao técnico do Laboratório de Neuroendocrinologia da Reprodução Feminina da Faculdade de Odontologia de Ribeirão Preto, Ruither de Oliveira Gomes Carolino e à professora Dra. Janete Aparecida Anselmo-Franci pelos materiais e ajuda com a dosagem de corticosterona.

Ao técnico do Laboratório de Endocrinologia de substâncias vasoativas, Marcelo Eduardo Batalhão e à professora Dra. Evelim Capelari Cárnio, pelos materiais doados e pela dosagem de nitrito/nitrato. 
A todos os outros colegas do laboratório, que mesmo que eu não cite um por um, contribuíram para a conclusão desta etapa.

À Leni Gomes Heck Bonagamba (in memoriam), que deixa um grande legado à ciência brasileira, por compartilhar com cuidado sua vasta experiência, pela paciência em ensinar a cirurgia de implante de cânula-guia no NTS, a perfusão do animal inteiro, bem como a realização de microinjeções, registros de animal acordado em câmara pletismográfica, confecção de cânulas, agulhas injetoras, e tantas outras coisas que aprendi no primeiro ano do mestrado. Agradeço pela companhia, pelos aniversários comemorados, e pelo acolhimento e abraços carinhosos. Que Deus a guie pela luz e permaneça ao seu lado, acolhendo-a com carinho, como ela sempre fez com todos a sua volta, e como ela sempre acreditou.

Aos colegas Drs. Mateus Ramos Amorim e George Miguel Perbone Souza, por me ensinarem a técnica de preparação coração tronco cerebral isolados, que utilizei por uma parte do mestrado.

Aos colegas de turma Priscilla Matter Borges e Heitor Bernardes Pereira Delfino, por tornarem nosso percurso, por ocasiões colorido. Ainda, agradeço a minha querida amiga Aline Alves de Jesus, por aquecer os dias mais frios com seu abraço. Agradeço à Dra. Melina Pires da Silva Moraes pela alegre companhia. Aos outros colegas do departamento e cursão, agradeço pelos momentos compartilhados.

Aos funcionários do biotério da Faculdade de Odontologia de Ribeirão Preto pelo trabalho desempenhado e disposição em ajudar.

Aos animais que fizeram parte do meu trabalho, pelas suas preciosas vidas.

À banca examinadora deste trabalho, por aceitar o convite para a avaliação e pelas contribuições.

Ao apoio financeiro da CAPES e da FAPESP. 


\section{RESUMO}

BORGES, G. S. Efeito do citral no choque endotoxêmico. 2018. 56f. Dissertação (Mestrado) - Faculdade de Medicina de Ribeirão Preto, Universidade de São Paulo, Ribeirão Preto, 2018.

A sepse é caracterizada por uma produção excessiva de mediadores inflamatórios, acompanhada de taquicardia e hipotensão. Experimentalmente, a administração de endotoxina (Lipopolissacarídeo, LPS) em doses relativamente elevadas induz choque endotoxêmico, sendo um bom modelo de estudo da sepse. Diversos grupos têm demonstrado ações antiinflamatórias e antitumorais do citral, um composto do óleo essencial de Cymbopogon citratus. Nosso laboratório demonstrou ação antipirética do citral em modelo de febre induzida por LPS, acompanhada de redução nos níveis de citocinas plasmáticas e de prostaglandina $\mathrm{E}_{2}\left(\mathrm{PGE}_{2}\right)$ no plasma e área pré óptica do hipotálamo (POA), importante região termorregulatória. A hipótese testada neste trabalho foi a de que o citral atenua a hipotensão provocada pela endotoxina, além de amenizar as alterações termoregulatórias. Todos os procedimentos foram executados de acordo com os princípios éticos de experimentação animal, aprovados pelo comitê de ética local (CEUA 2015.11214 58-2). Foi realizado o implante de cânulas na artéria e veia femoral para registro da pressão arterial e administração de LPS $(1,5 \mathrm{mg} / \mathrm{kg})$ ou salina apirogênica $0,9 \%$ além do implante de datalogger na cavidade peritoneal de ratos Wistar, para registro da temperatura corporal. No dia do registro, 30 minutos antes da administração de LPS ou salina, os animais receberam citral $(100 \mathrm{mg} / \mathrm{kg}$ ) ou tween 80 a $1 \%$ (veículo) por via oral. Os parâmetros cardiovasculares e temperatura corporal foram registrados por 300 minutos após os respectivos tratamentos. Os valores de pressão arterial média (PAM) e frequência cardíaca (FC) foram coletados a cada 10 minutos após o tratamento e a temperatura corporal foi registrada pelo datalogger em intervalos de 5 minutos. Em outro protocolo foi realizado apenas o implante de cânula na veia femoral dos animais de todos os grupos para administração de LPS ou salina, coleta de sangue para dosagem de interleucina $6, \mathrm{PGE}_{2}$, nitrito e nitrato e corticosterona e coleta do encéfalo para dosagem de $\mathrm{PGE}_{2}$ e $\mathrm{PGD}_{2}$. As diferenças estatísticas entre os grupos foram analisadas pelo teste ANOVA two-way seguido por pós teste de Newman-Keuls, com o nível de significância adotado de $\mathrm{p}<0,05$. A administração de LPS provocou queda na PAM e 
aumento na FC. Tais respostas não foram afetadas pela administração prévia de citral. O LPS também induziu febre e aumento nas concentrações plasmáticas de interleucina - 6 (IL-6), óxido nítrico (NO), $\mathrm{PGE}_{2}$ e corticosterona. Esses parâmetros não foram alterados pela préadministração de Citral. No entanto, o citral provocou redução na produção de $\mathrm{PGD}_{2}$ naPOA, sem alterar a de $\mathrm{PGE}_{2}$ nesta região. Podemos concluir que o citral não previne as alterações nos parâmetros cardiovasculares no modelo de endotoxemia em ratos, porém reduz a produção de um mediador termorregulatório e inflamatório do sistema nervoso central (a $\mathrm{PGD}_{2}$ ), sem alterar a produção de outros mediadores inflamatórios a nível periférico (no plasma). Portanto, em um modelo mais agressivo de inflamação sistênica o citral não se mostrou suficiente para proteger o organismo das ações deletérias do LPS.

Palavras-chave: Choque séptico, Termorregulação, Citocinas inflamatórias, prostaglandinas, Lipopolissacarídeo. 


\begin{abstract}
BORGES, G. S. Effect of citral on endotoxemic shock. 2018. 56f. Dissertation (Masters) Ribeirão Preto Medical School, University of São Paulo, Ribeirão Preto, 2018.
\end{abstract}

Sepsis is characterized by the overproduction of inflammatory mediators, accompanied by tachycardia and hypotension. Experimentally, administration of endotoxin (Lipopolysaccharide, LPS) in relatively high doses induces endotoxemic shock, a widely used model of sepsis in rats. Several groups have demonstrated anti-inflammatory and antitumor roles of citral, an essential oil compound of Cymbopogon citratus. Emilio-Silva et al. (2017) have shown an antipyretic role of citral in a model of LPS-induced fever, accompanied by a reduction of cytokines and prostaglandin $\mathrm{E}_{2}$ plasma levels and in the preoptic area of hypothalamus (POA), the hierarchically most important thermoregulatory region. We hypothesized that citral attenuates the LPS-induced hypotension, besides mitigating the thermoregulatory adjustments in rats. All procedures were performed in agreement with ethical guidelines for animal experimentation aproved by the local ethical committee (CEUA 2015.11214 58-2). Femoral artery and vein were implanted with cannulas for blood pressure recording and LPS $(1.5 \mathrm{mg} / \mathrm{kg})$ or $0.9 \%$ apyrogenic saline injection. In a second surgical procedure a datalogger was implanted into the peritoneal cavity for measurements of body temperature. All surgical procedures were performed under Ketamin/xilazin (100/10 mg/kg) anesthesia. One day after arterial catheterization, 30 minutes prior to LPS or saline administration, the animals received either citral $(100 \mathrm{mg} / \mathrm{kg})$ or $1 \%$ tween 80 (vehicle) oralstarly. The cardiovascular parameters and body temperature were recorded for 300 minutes after the respective treatments. Mean blood pressure (MAP) and heart rate (HR) were collected every 10 minutes after treatments and body temperature was recorded by the datalogger at 5 minute intervals. Blood samples were obtained in another set of rats for interleukin-6, $\mathrm{PGE}_{2}$, nitrite and nitrate and corticosterone analyses. The brain was removed for $\mathrm{PGE}_{2}$ and $\mathrm{PGD}_{2}$ analyses. Statistical differences between groups were analyzed by the two-way or one-way ANOVA test followed by Newman-Keuls post-test, with significance level adopted at $\mathrm{p}<0.05$. As expected, LPS administration caused a decrease in MAP and an increase in HR, and these responses were not affected by citral. LPS also induced fever and increased plasma levels of interleukin - 6 (IL - 6), nitric oxide (NO), prostaglandin E 2 and 
corticosterone. These parameters were also not altered by citral. On the other hand, citral caused a reduction in prostaglandin $\mathrm{D}_{2}$ concentration in the $\mathrm{POA}$, but failed to alter $\mathrm{PGE}_{2}$ levels in this region. Our data are consistent with the notion that citral does not affect changes in cardiovascular and thermoregulatory parameters. Consistently, citral also caused no changes in both LPS-induced peripheral inflammatory mediators (in plasma) and in the POA, except $\mathrm{PGD}_{2}$. Therefore, in our model which mimetic a fairly critical situation, citral may not be sufficient to protect the organism from the deleterious actions of LPS. Financial support: FAPESP / CAPES.

Key words: Septic shock, Thermoregulation, proinflammatory cytokine, prostaglandins, Lipopolysaccharide. 


\section{LISTA DE ABREVIATURAS}

ANOVA Análise de variância

AP-1 Proteína ativadora - 1

APO Área pré-óptica

CD14 Cluster of differentiation 14

DAMPs Padrões moleculare associados ao dano

EDTA Ácido etileno diamino tetra-acético

EPM Erro padrão da média

HHA Hipotálamo-hipófise-adrenocortical

ICAM Intercellular Adhesion Molecule

IL-1 $\beta \quad$ Interleucia - $1 \beta$

IL-6 Interleucina - 6

INOS Óxido nítrico sintase induzível

IRAK IL-1 receptor-associated kinase

IRF3 Interferon regulatory factor 3

LBP Proteína ligadora de LPS

MAPK Mitogen-activated protein kinase

MD2 Proteína de diferenciação mielóide

MYD88 Myeloid differentiation primary response 88

NFкB Factor nuclear kappa B

NO Óxido nítrico

PAM Pressão Arterial Média

PAMPs Padrões moleculares associados a patógenos

PAP Pressão Arterial Pulsátil

$\mathrm{PGD}_{2} \quad$ Prostaglandina $\mathrm{D}_{2}$

$\mathrm{PGE}_{2} \quad$ Prostaglandina $\mathrm{E}_{2}$

POA Área Pré-óptica do hipotálamo

PRR Receptores de reconhecimento padrão

STAT Signal transducers and activators of transcription

Tc Temperatura corporal

TIRAP TIR domain-containing adaptor protein

TLR4 Toll Like receptor -4 
TNF- $\alpha \quad$ Fator de necrose tumoral $\alpha$

VCAM Vascular cell adhesion molecule 


\section{LISTA DE FIGURAS}

Figura 1. Esquema representativo do desenvolvimento da sepse 20

Figura 2. Esquema representativo dos elementos de controle da temperatura corporal 22

Figura 3. Alterações cardiovasculares durante a sepse 24

Figura 4. Grupos experimentais 33

Figura 5. Desenho experimental 1 34

Figura 6. Desenho experimental 2 34

Figura 7. Retirada das amostras da área pré-óptica do hipotálamo 35

Figura 8. Pressão arterial dos animais submetidos à injeção i.v. de LPS comparada com a dos animais controle 38

Figura 9. Frequência cardíaca dos animais submetidos à injeção i.v. de LPS comparada com a dos animais controle. .39

Figura 10. Pressão arterial média e frequência cardíaca dos animais dos grupos TSAL,

CSAL, TLPS e CLPS em função do tempo.

Figura 11. Concentração plasmática de Nitrito e Nitrato aos 150 minutos após o trata mento com LPS ou salina.

Figura 12. Perfil temporal da resposta de temperatura corporal. . .42

Figura 13. Concentração plasmática de Interleucina - 6 aos 150 minutos após o tratamen to com LPS ou salina.

Figura 14. Concentração plasmática de Corticosterona aos 150 minutos após o tratamen to com LPS ou salina. .44

Figura 15. Concentração plasmática de $\mathrm{PGE}_{2}$ aos 150 minutos após o tratamento com LPS ou salina. .45

Figura 16. Concentração plasmática de $\mathrm{PGE}_{2}$ e PGD2 na POA aos 150 minutos após o 


\section{SUMÁRIO}

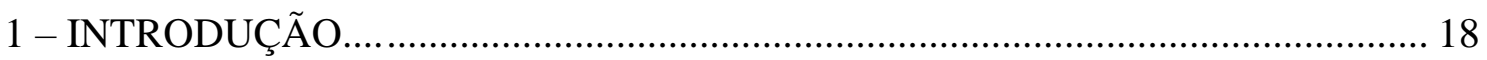

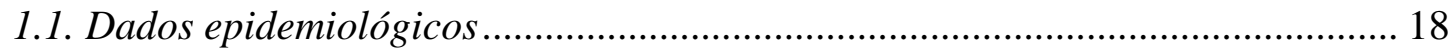

1.2. Definição e fisiopatologia da sepse ............................................................... 19

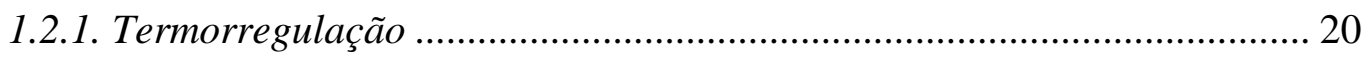

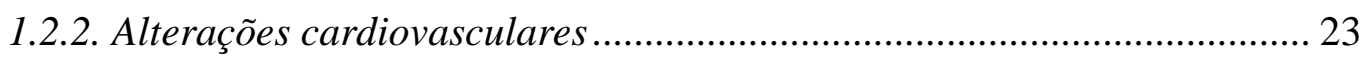

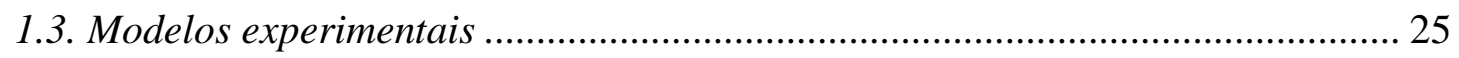

1.3.1. Mecanismo de ação do LPS .................................................................. 25

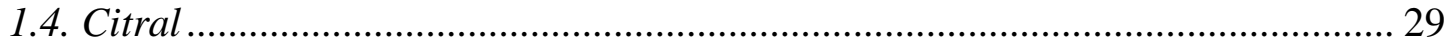

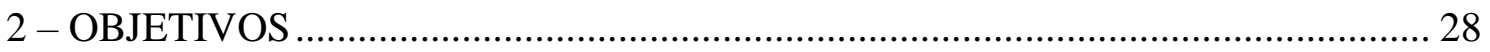

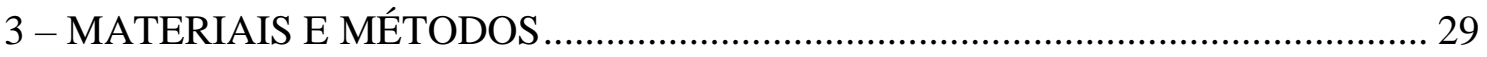

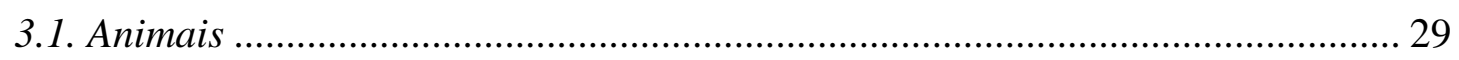

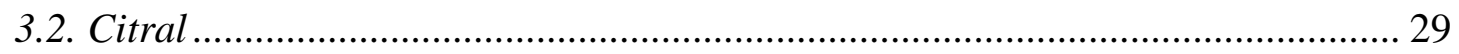

3.3. LPS

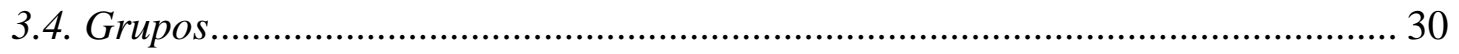

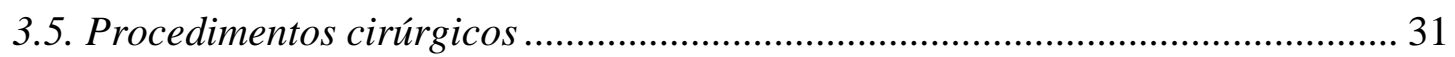

3.5.1. Implante de cápsula de temperatura datalogger ....................................... 36

3.5.2. Implante de cânula arterial e venosa …………………………………….... 36

3.6. Registro das variáveis cardiovasculares e temperatura corporal........................ 32

3.6.1. Registro dos parâmetros cardiovasculares................................................ 36

3.6.2. Registro da temperatura corporal.............................................................. 36

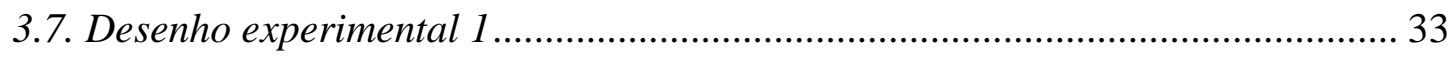

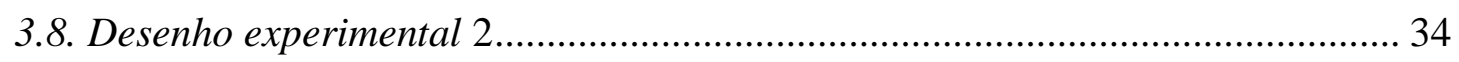

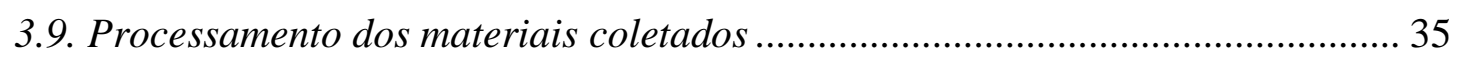

3.10. Dosagem dos produtos da oxidação do óxido nítrico (NOx) ............................. 29

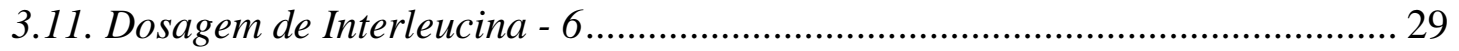

3.12. Dosagem de Prostaglandina E $E_{2}$ plasmática e na POA ....................................... 29

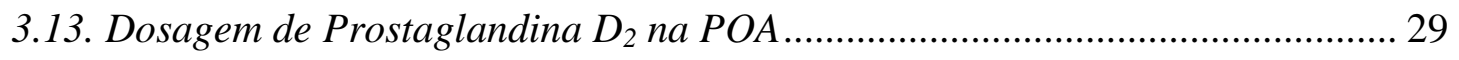

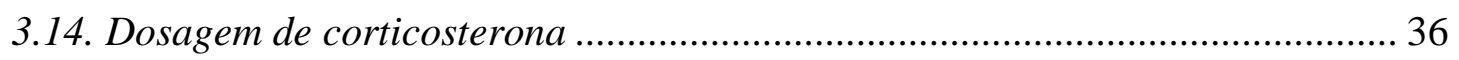

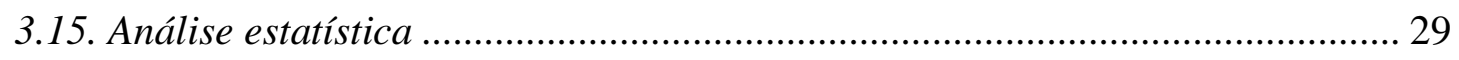

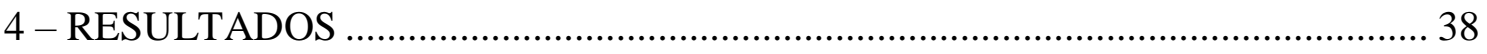


4.1. Caracterização do modelo......

4.2. Influência do citral na pressão arterial, frequência cardíaca e produção de óxido nítrico 38

4.3. Influência do citral na regulação da temperatura corporal ................................ 41

4.4. Análise dos mediadores inflamatórios no plasma ............................................... 42

4.5. Análise dos mediadores inflamatórios na POA .................................................... 45

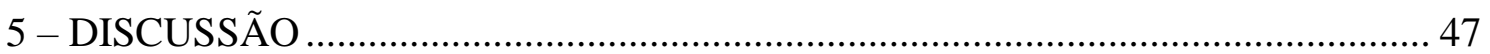

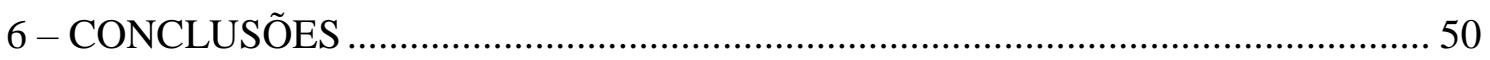

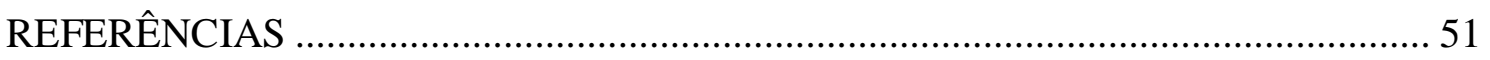




\section{1 - INTRODUÇÃO}

O termo sepse é derivado da palavra grega sepsis, que originalmente era usada para denominar a "decomposição de matéria orgânica animal ou vegetal, na presença de bactéria". Esse termo foi encontrado pela primeira vez nos poemas de Homero, a mais de 2700 anos, onde sepse é um derivado da palavra sepo, cujo significado é "eu apodreço" (GEROULANOS; DOUKA, 2006). O conceito de sepse passou por várias modificações ao longo dos anos, pois os níveis de gravidade dessa condição e a presença de diferentes sinais determinavam diferentes classificações que possuíam nomenclatura diferente. Atualmente são utilizados os conceitos sepse e choque séptico.

\subsection{Dados epidemiológicos}

Apesar dos avanços no entendimento da patogênese da sepse e os cuidados no tratamento, os estudos epidemiológicos atuais indicam que essa condição continua um grande desafio em todas as regiões econômicas (FLEISCHMANN et al., 2016). Numa revisão sistemática elaborada por Fleischmann et al., (2016) foram analisados estudos epidemiológicos de nível populacional em todo o mundo. Os autores constataram que os estudos sobre a incidência e letalidade por sepse são escassos e muitas vezes inexistentes em países de média e baixa renda. Embora com essa limitação, uma extrapolação dos dados provenientes de países desenvolvidos, assumindo que as taxas de sepse e sepse grave (antiga classificação) estimadas se aplicassem aos países de média e baixa renda, um número total de 31,4 milhões de casos, contando os dois níveis de gravidade, poderiam ser esperados em uma população global de 7,2 bilhões de pessoas. Se estimados os valores com base apenas na última década, estimados 50,9 milhões de casos seriam tratados em hospitais ao redor do mundo. Por fim, levando-se em conta apenas os casos mais severos e fatais da última década, a estimativa de incidência global é que a sepse poderia contribuir com mais de 5,3 milhões de mortes em torno do mundo, por ano.

Até o ano passado, os poucos estudos epidemiológicos que mostraram a incidência e índice de mortalidade por sepse no Brasil datavam de mais de uma década, os estudos multicêntricos BASES, Sepse Brasil e COSTS. O estudo COSTS, utilizando dados de 2003 
e 2004, apontou um dado interessante, de que a letalidade devido à sepse era maior $(49,1 \%)$ em hospitais vinculados ao sistema de saúde público em relação ao privado $(36,7 \%)$, o que foi vinculado por Conde et al., (2013) ao reconhecimento tardio da sepse mais frequente em instituições públicas. Estudos subsequentes não fizeram essa comparação para dados mais atuais. Em 2017 um conjunto de pesquisadores de diferentes centros de pesquisa publicou um estudo observacional sobre a prevalência de sepse no Brasil que mostrou que, quase $30 \%$ dos leitos das UTIs brasileiras estão ocupadas com pacientes em sepse ou choque, com mortalidade de 55,4\% (MACHADO et al., 2017). Segundo o conselho federal de medicina e o Instituto Latino-americano de sepse as estimativas indicam a existência de aproximadamente 600 mil novos casos de sepse a cada ano no Brasil, que podem ser atribuídos a vários aspectos, como a maior resistência de microorganismos aos medicamentos, a falta de infraestrutura de atendimento em prontos-socorros e hospitais, o aumento no número de acidentes de trânsito e o crescimento da população idosa e de pacientes imunossuprimidos (CARDOSO, 2001; FRACASSO, 2008). Tal população representa um grupo mais vulnerável ao desenvolvimento de infecções graves (CARDOSO, 2001).

\subsection{Definição e fisiopatologia da sepse}

O terceiro consenso internacional para definição de sepse e choque séptico, publicado recentemente, definiu a sepse como uma disfunção orgânica potencialmente fatal causada por uma resposta desregulada do hospedeiro a uma infecção (SINGER, M. et al., 2016). Ainda de acordo, o choque séptico ocorre quando o indivíduo com sepse apresenta anormalidades circulatórias, celulares e metabólicas profundas o suficiente para aumentar o risco de mortalidade para além do que apenas com sepse.

O sistema imune inato dos mamíferos é capaz de detectar bactérias quando elas adentram a corrente sanguínea ou tecidos locais e iniciar uma resposta imune logo em seguida (LAZARUS, 2006). Em muitos casos o sistema imune é eficiente em elaborar uma resposta protetora contra a infecção, que resulta na eliminação do patógeno e retorno à homeostase sem destruição de tecidos saudáveis. Porém, com a prevalência do patógeno (ou uma alta concentração de endotoxina, por exemplo) a resposta imune é multiplicada e desbalanceada, provocando danos teciduais por meio de seus efeitos no endotélio, epitélio e células do 
sistema imune que podem ser irreversíveis e culminar com a morte (BURAS; HOLZMANN; SITKOVSKY, 2005; VAN DER POLL et al., 2017). A Figura 1 ilustra esse processo.

Durante a sepse a resposta do hospedeiro tem como característica a inflamação excessiva e em um segundo momento, supressão imune. A inflamação é mediada em parte por meio da produção e liberação de mediadores inflamatórios por diferentes células [por exemplo citocinas pró inflamatórias, onde destacam-se o TNF- $\alpha$ (Fator de necrose tumoral- $\alpha$ ), IL-6 e IL-1 $\beta$ (interleucina 6 e 1 $\beta$, respectivamente)], a ativação dos sistemas de coagulação e complemento e do endotélio vascular. Tais respostas levam a danos celulares que provocam a liberação de padrões moleculares associados ao dano (do inglês DAMPs - damage-associated molecular patterns), levando a lesões teciduais, disfunção orgânica, catabolismo e morte celular (VAN DER POLL et al., 2017).

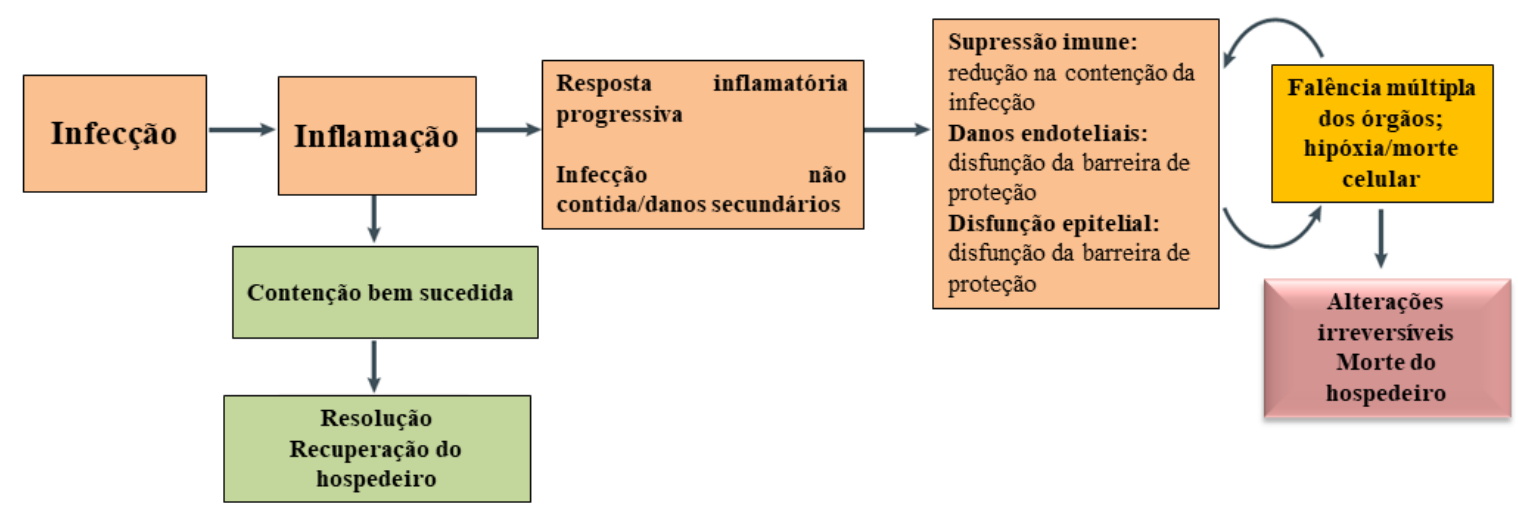

Figura 1. A sepse se desenvolve a partir de uma infecção ou um estímulo inflamatório que o hospedeiro não consegue conter. Esse desbalanço na resposta inflamatória leva à desorganização e danos no sistema imune. A barreira de proteção constituída por células endoteliais e epiteliais, quando danificada, permite disseminação da infecção, gerando propagação da disfunção imune, resultando em falência múltipla dos órgãos, e frequentemente um estado irrecuperável e morte (Adaptada de Buras et al., 2005).

\subsubsection{Termorregulação}

Sabe-se que a temperatura corporal (Tc) é um importante fator responsável por alterar funções fisiológicas em nosso organismo, devido a sua interferência em processos bioquímicos, como a velocidade de reações químicas que ocorrem a todo o momento em nosso organismo. 
Os mamíferos são animais endotérmicos, que regulam sua própria temperatura de maneira independente da temperatura ambiente, mantendo-a constante (BRANCO; SORIANO; STEINER, 2014), de forma que os processos bioquímicos no organismo não sejam afetados. Quando expostos a uma condição de desafio, como uma infecção, os sistemas responsáveis pela regulação da nossa temperatura lançam mão de uma série de ajustes, que desviam o organismo do estado eutérmico (Tc mantida em níveis considerados normais), para o estado de febre (aumento regulado da Tc) ou anapirexia (redução regulada da Tc) (BRANCO; SORIANO; STEINER, 2014).

A temperatura corporal é monitorada continuamente por neurônios especializados denominados termorreceptores centrais, localizados em diferentes locais do sistema nervoso central, como a medula espinal, formação reticular e hipotálamo, mais especificamente na área pré-óptica do hipotálamo (POA), uma região que além de conter neurônios termossensíveis, recebe projeções de neurônios termorreceptores de outras áreas e também é o destino final de projeções de termorreceptores periféricos (BOULANT, 1998, 2000) localizados na pele, responsáveis pelo monitoramento da temperatura ambiente. Dessa maneira, neurônios da POA agem como integradores da sensibilidade térmica, comparando informações centrais e periféricas, sendo também responsáveis por gerar respostas termorregulatórias adequadas para as condições internas e ambientais em que o organismo se encontra (Figura 2). Além disso, os neurônios termossensíveis da POA podem ser afetados por substâncias endógenas capazes de promover alterações na temperatura corporal (BOULANT, 2000), por isso chamadas de pirógenos endógenos, como as citocinas produzidas durante a sepse. 


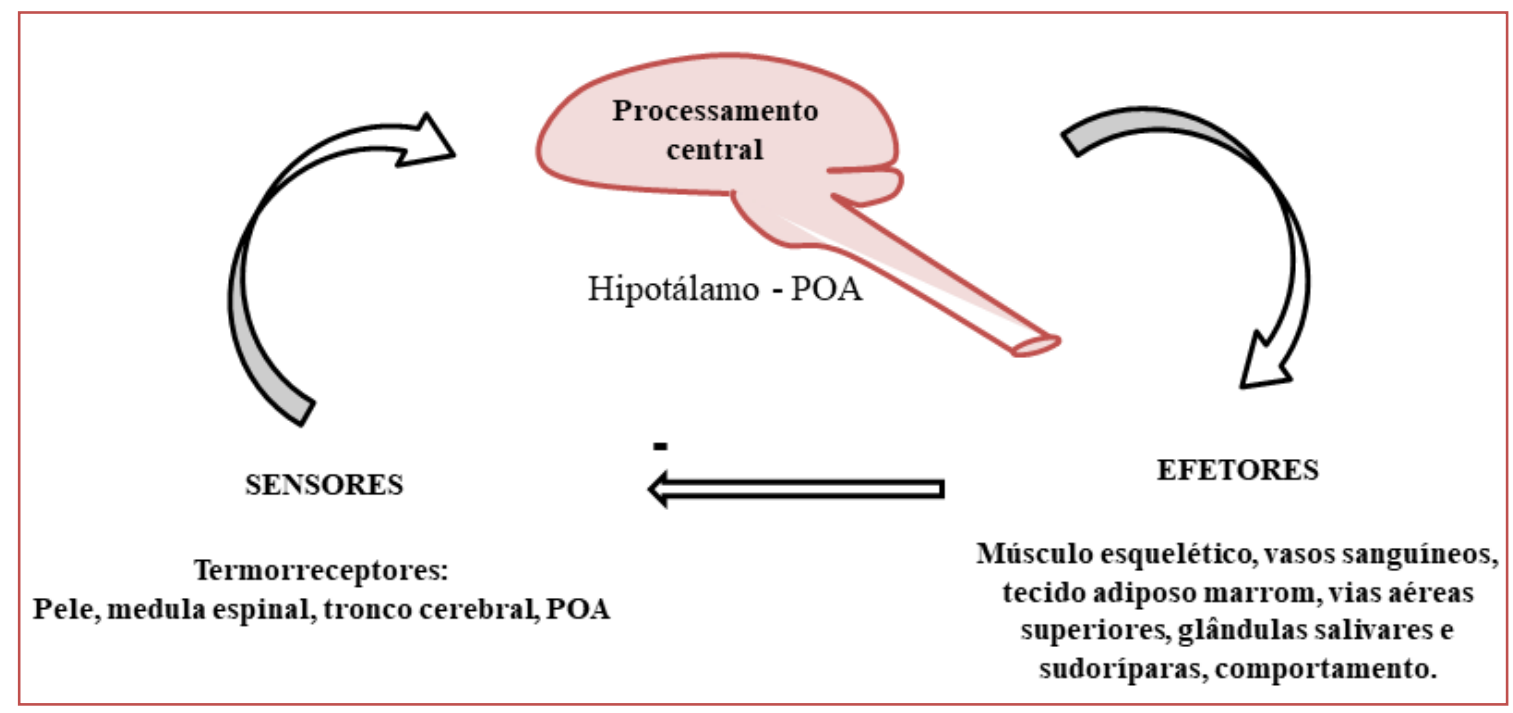

Figura 2. Esquema representativo dos elementos do sistema de controle da temperatura corporal. A informação proveniente dos sensores alcança o sistema de processamento, cuja saída comanda a atividade dos termoefetores. [Modificada de Bicego; Barros e Branco (2007)].

A febre, gerada e controlada na POA, favorece a atividade do sistema imune, sendo uma resposta de defesa bastante importante. Por isso, a febre representa o principal indicador da presença de infecção (KWIATKOSKI et al., 2013). A prostaglandina $\mathrm{E}_{2}\left(\mathrm{PGE}_{2}\right)$ tem sido considerada o principal mediador da febre, que induz aumento da Tc quando injetada diretamente no órgão vasculoso da lâmina terminal (OVLT) e na POA (OKA, 2004). No entanto, Blatteis et al. (2005) postularam um modelo baseado em uma cuidadosa revisão, que dividia a febre em resposta ao LPS em duas fases. A sequencia de eventos que culminariam com a febre foi elaborada como se segue: o primeiro passo é a ativação imediata da cascata do complemento pelo LPS, seguido da estimulação das células de Kupffer no fígado com liberação de $\mathrm{PGE}_{2}$, a excitação de aferentes vagais, sua transmissão de sinal para a POA via feixe noradrenérgico ventral e a consequente ativação de receptores adrenérgicos neuronais e gliais pela liberação de noradrenalina. Essa sequencia seria responsável pelo imediato aumento na Tc, de maneira independente da $\mathrm{PGE}_{2}$, resposta chamada de fase inicial da febre. A fase tardia seria dependente de $\mathrm{PGE}_{2}$ produzida em resposta ao aumento na atividade da COX-2 (ciclooxigenase 2 - forma induzível) secundária a ativação pelas citocinas plasmáticas liberadas em resposta ao LPS, que alcançam pequenas vênulas em torno de células perivasculares endoteliais do cérebro, particularmente mais densas na POA, na base do hipotálamo, medula ventrolateral e no núcleo do trato solitário (BLATTEIS et al., 2005; BLATTEIS, 2006; SAPER; ROMANOVSKY; SCAMMELL, 2012). 
Já é conhecido da literatura científica que a anapirexia pode ocorrer em diferentes situações, como desidratação, hipoglicemia, intoxicação, hipóxia e sepse (GIUSTI-PAIVA et al., 2002; ALMEIDA et al., 2006; BICEGO; BARROS; BRANCO, 2007; KRALL et al., 2010). A maior parte dos estudos a respeito da anapirexia tem tratado dessa resposta frente ao desafio hipóxico, que resultaria de um equilíbrio entre seus indutores [óxido nítrico (NO), serotonina, dopamina, adenosina] e inibidores [monóxido de carbono (CO)] agindo em neurônios da POA como revisado por Bicego; Barros e Branco (2007).

Em modelos experimentais de inflamação sistêmica induzida por LPS em ratos, a dinâmica da resposta termorregulatória depende de vários fatores, como a temperatura ambiente e a dose de endotoxina administrada. Em uma zona considerada termoneutra, o LPS intravenoso em baixas doses tipicamente causa uma febre monofásica, enquanto doses moderadas a altas disparam aumentos sequenciais na temperatura corporal, caracterizando a febre polifásica. Experimentos realizados na zona sub-termoneutra a resposta ao LPS intravenoso evoca febre em baixas doses, hipotermia moderada seguida por febre em doses intermediárias, e hipotermia profunda em doses altas, indutoras de choque (ROMANOVSKY; IVANOV; SHIMANSKY, 2002; RUDAYA et al., 2005).

Em 1979, Shimizu et al., (1979) relataram que a prostaglandina $\mathrm{D}_{2}\left(\mathrm{PGD}_{2}\right)$ pode ser encontrada em concentrações relativamante altas no encéfalo. Pouco tempo depois, foi atribuído à $\mathrm{PGD}_{2}$ o papel de indutora do sono (UENO et al., 1982b, 1983). Além disso, com a utilização de microinjeções, Ueno et al., (1982a) demonstraram que a $\mathrm{PGD}_{2}$ participa da fase de redução da temperatura corporal induzida por LPS, caracterindo-se assim a sua ação importante como agente criogênico. De modo consistente com este achado, recentemente, Krall et al., (2010) observaram que a $\mathrm{PGD}_{2}$ é um mediador essencial para a queda da temperatura corporal observada durante o desafio imune após a deprivação alimentar.

\subsubsection{Alterações cardiocirculatórias}

O choque endotoxêmico é caracterizado por uma intensa vasodilatação arteriolar periférica resistente a agentes vasopressores, que pode estar associada à disfunção cardíaca, taquicardia, disfunção sistólica, e outros (OGNIBENE et al., 1988). A hipotensão gerada é 
responsável por aumentar o número de óbitos de pacientes com sepse, devido à evolução do quadro para falência múltipla dos órgãos (KARIMA et al., 1999).

Animais experimentais submetidos à administração de doses relativamente altas de LPS apresentam hipotensão e taquicardia (GIUSTI-PAIVA; CASTRO; ANTUNES-RODRIGUES, 2002; SAIA et al., 2013). Esses autores observaram uma queda inicial na pressão arterial próximo de uma hora após a injeção intravenosa de LPS. A pressão então sofre um pequeno aumento seguido à queda inicial e volta a cair, se mantendo baixa até 6 horas após a injeção. A frequência cardíaca sofre um aumento logo após a administração da endotoxina que é mantido.

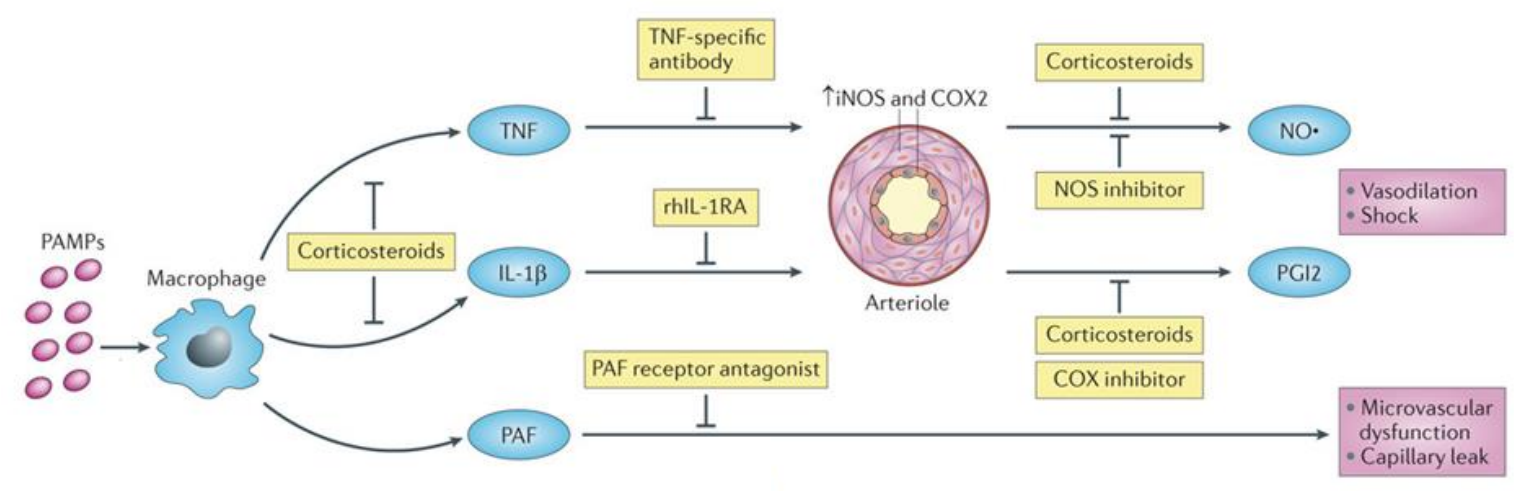

Figura 3. Vias que levam à disfunção microvascular, vasodilatação resistente a agentes vasopressores e hipotensão. (Adaptada de Fink; Warren, 2014)

As vias que levam a disfunção da microvasculatura, vasodilatação e choque se iniciam com a ligação de padrões moleculares associados a patógenos (PAMPs), sendo o LPS um PAMP presente ou liberado por bactérias gram-negativas que infectam o organismo. A interação dos PAMPs com seus receptores de reconhecimento padrão (PRR) presentes nos macrófagos disparam a liberação de TNF- $\alpha$, IL-1 $\beta$, que, entre outros mediadores inflamatórios, levam ao aumento na expressão de iNOS (óxido nítrico sintase induzível, a isoforma da enzima responsável pela produção de óxido nítrico em resposta à desafios do sistema imune) e COX-2 nas células endoteliais e do músculo liso vascular, promovendo aumento na produção do radical livre NO e prostaglandina $\mathrm{I}-2$, potentes mediadores vasoativos que provocam vasodilatação e choque (TITHERADGE, 1999; FINK; WARREN, 2014). O processo descrito acima é representado na Figura 3. 


\subsection{Modelos experimentais para estudo da sepse}

Existem diversos modelos para estudo da sepse em laboratório, que podem ser classificados em três grupos, no que diz respeito ao agente indutor, são eles: administração exógena de toxina, administração exógena de um patógeno vivo ou alterações na barreira de proteção endógena do animal, como os que permitem a migração de bactérias do intestino para a corrente sanguínea, sendo um exemplo o modelo de ligação cecal e perfuração (CLP) (BURAS; HOLZMANN; SITKOVSKY, 2005). Um dos modelos mais comumente utilizado é a administração intraperitoneal ou intravenosa de Lipopolissacarídeo (LPS) (NEMZEK; HUGUNIN; OPP, 2008), uma endotoxina proveniente da membrana externa de bactérias gram-negativas, devido à sua reprodutibilidade e fácil padronização. Para estudo da sepse são necessárias doses relativamente altas de LPS, que variam de acordo com a origem da endotoxina e o modelo animal (BURAS; HOLZMANN; SITKOVSKY, 2005; NEMZEK; HUGUNIN; OPP, 2008). A dose de $2,5 \mathrm{mg} / \mathrm{kg}$ administrada por via intraperitoneal produziu respostas satisfatórias observadas em nosso laboratório (FERNÁNDEZ et al., 2016), enquanto outros laboratórios padronizaram a dose de 1,5 mg/kg quando o LPS é administrado por via intravenosa (GIUSTI-PAIVA et al., 2002; SAIA et al., 2013).

\subsubsection{Mecanismo de ação do LPS}

Há várias décadas o LPS já era reconhecido como um princípio tóxico fortemente ligado à parede celular de bactérias gram-negativas que exercia ações biológicas principalmente após sua liberação devido à desintegração da célula bacteriana e, por isso, já era denominado como endotoxina (WESTPHAL et al., 1981). O LPS é liberado tanto pela morte quanto pela divisão celular. Estruturalmente, ele pode ser dividido em uma parte central composta por uma cadeia de polissacarídeos e pelo antígeno - $\mathrm{O}$ e um domínio hidrofóbico conhecido como lipídio A (ULEVITCH; TOBIAS, 1995). A indução das respostas biológicas características da endotoxemia tem sido atribuída à porção do LPS correspondente ao lipídio A (RIETSCHEL et al., 1994). Diferentes classes de patógenos microbianos apresentam padrões moleculares associados a patógenos que são reconhecidos por receptores de reconhecimento padrão. Tem sido demonstrado que o receptor de reconhecimento padrão responsável pela sinalização do LPS é o receptor do tipo Toll - 4 (TLR4 - Toll like receptor 4) (MOGENSEN, 2009). 
Quando o LPS atinge a corrente sanguínea ele se liga à proteína ligadora de LPS (LBP) e então ao co-receptor CD14, uma proteína ligada ao glicosilfosfatidilinositol expressa na superfície celular de fagócitos. A CD14 existe também em sua forma solúvel. O LPS é então transferido para o TLR4 complexado com uma proteína acessória em sua porção extracelular, a proteína de diferenciação mieloide 2 (Myeloid Differentiation Protein 2 - MD2). A dimerização desse complexo TLR4-MD2 induz a formação de uma estrutura de proteínas sinalizadoras composta de TIRAP (do inglês TIR domain-containing adaptor protein), MyD88 (Myeloid differentiation primary response 88), e IRAK (IL-1 receptor-associated kinase) no domínio tirosina do TLR4, ativando a via de sinalização que leva a produção de citocinas pró-inflamatórias (AKIRA; UEMATSU; TAKEUCHI, 2006; PŁÓCIENNIKOWSKA et al., 2015). Além da sinalização descrita acima, diferentes outras vias podem ser ativadas pela ligação do LPS ao TLR4. Alguns exemplos são as vias da MAP quinase (MAPK, do inglês mitogen-activated protein Kinase), AP-1 (activator protein 1 ), STAT (signal tranducer and activator of transcription), IRF3 (interferon (IFN)-regulatory factor 3), NFאB (Nuclear Factor kappa B), sendo esta última uma das principais, que dentro do núcleo da célula, é capaz de promover a transcrição de genes que participam de diversos processos fisiológicos e fisiopatológicos (CRUZ-MACHADO, 2010).

\subsection{Citral}

O citral é uma mistura racêmica de dois enantiômeros, os monoterpenóides nerol e geraniol. Ele está presente em óleos essenciais de diversas espécies de plantas, sendo o principal componente do popularmente chamado capim limão (Cymbopogon citratus) (NISHIJIMA et al., 2014a).

Vários estudos tem demonstrado diferentes papeis do citral em sistemas biológicos tanto in vitro quanto in vivo. Em modelo de inflamação induzida por LPS em células endoteliais da veia umbilical humana, Song et al. (2016) observaram redução da expressão de VCAM (molécula de adesão celular vascular) e ICAM (molécula de adesão celular intercelular) quando o citral foi adicionado junto com LPS no meio de cultura. Além disso, esses autores observaram diminuição da adesão de neutrófilos nessas células quando estimuladas com LPS e tratadas com citral. Outro resultado interessante foi obtido em modelo de peritonite, onde o citral promoveu redução na atividade da mieloperoxidase no tecido peritoneal, bem como nos níveis das citocinas pró inflamatórias TNF- $\alpha$ e IL-6, de maneira dose-dependente. 
Um estudo realizado recentemente demonstrou que o citral e seus isômeros constituintes, quando administrados na forma de nanopartículas micelares, foi capaz de reduzir o crescimento de células tumorais em camundongos, um achado importante que lança a necessidade de mais estudos envolvendo esse composto no tratamento do câncer (KAPUR et al., 2016).

Apesar da variedade de estudos envolvendo o citral, nenhum estudo havia sido conduzido para avaliar sua possível atividade antipirética, devido às suas ações anti-inflamatórias. Com base na relação entre inflamação e pirogênese, um recente trabalho publicado por EmílioSilva et al. (2017) investigou os efeitos do citral na febre induzida por baixa dose de LPS. Os resultados observados permitiram concluir que o citral possui uma ação antipirética, reduzindo a febre em animais que receberam esse composto por via oral antes da injeção intraperitoneal de LPS. Esse resultado pôde ser explicado pelo efeito anti-inflamatório observado com a redução nos níveis de citocinas plasmáticas IL-1 $\beta$, IL-6 e TNF- $\alpha$, bem como na concentração de $\mathrm{PGE}_{2}$ tanto no plasma, quanto na POA.

Com base nesses achados, este trabalho buscou verificar se em um modelo de inflamação sistêmica mais agressivo, o choque endotoxêmico, o citral também seria capaz de prevenir as alterações centrais e periféricas exageradas características do modelo. 


\section{2 - OBJETIVOS}

O presente trabalho teve como objetivo principal verificar se as alterações cardiovasculares e termorregulatórias induzidas pelo choque endotoxêmico são prevenidas pela ação do citral.

Utilizando o modelo de choque endotoxêmico produzido por dose relativamente alta de LPS $(1,5 \mathrm{mg} / \mathrm{kg})$ i.v. também buscamos identificar os mecanismos responsáveis pelo possível efeito do citral nos parâmetros cardiovasculares (pressão arterial e frequência cardíaca) e temperatura corporal por meio da análise de uma importante citocina próinflamatória (Interleucina 6) e de dois prostanoides envolvidos em processos inflamatórios e na regulação da temperatura corporal, as prostaglandinas $\mathrm{E}_{2}$ e $\mathrm{D}_{2}$, tanto no sistema nervoso central, na POA, quanto periférico (plasma). Além disso, buscamos investigar se o possível papel do citral poderia envolver alterações na atividade da enzima iNOS, levando à mudanças na produção de NO, por meio da dosagem de seus produtos de oxidação - Nitrito e Nitrato, e na regulação do eixo Hipotálamo-hipófise-adrenocortical (HHA), por meio da dosagem de corticosterona plasmática. 


\section{3 - MATERIAIS E MÉTODOS}

Os experimentos foram realizados no Laboratório de Neuroquímica da Inflamação Sistêmica do Departamento de Fisiologia da Faculdade de Medicina de Ribeirão Preto (FMRP-USP) e Departamento de Morfologia, Fisiologia e Patologia Básica da Faculdade de Odontologia de Ribeirão Preto (FORP-USP). Todos os procedimentos experimentais foram conduzidos de acordo com os Princípios Éticos em Experimentação Animal adotado pelo Conselho Nacional de Controle e Experimentação Animal (CONCEA), com base nos princípios de boas práticas de laboratório e procedimentos científicos, e com a aprovação do Comitê de Ética em Experimentação Animal da FORP-USP, protocolo nº 2015.1.788.58.5.

\subsection{Animais}

Foram utilizados ratos machos da linhagem Wistar, pesando entre 290 e 350g, provenientes do Biotério da Prefeitura do Campus Administrativo da USP de Ribeirão Preto (PCARP). Os animais foram mantidos em grupos de até cinco por caixa (Comprimento $41 \mathrm{~cm}$ x Largura $34 \mathrm{~cm}$ x Altura $16 \mathrm{~cm}$ ), no Biotério Setorial da Faculdade de Odontologia de Ribeirão Preto, recebendo dieta balanceada (NUVLAB CR1 - NUVITAL) para roedores e água ad libitum em ambiente com ciclo claro/escuro de 12 horas, à temperatura de $24 \pm 2^{\circ} \mathrm{C} \mathrm{e}$ umidade de $\pm 55 \%$. Todos os animais permaneceram nestas condições ambientais, por pelo menos $24 \mathrm{~h}$ antes de qualquer procedimento cirúrgico.

\subsection{Citral}

O Citral (Sigma, St.Louis , MO, EUA) era preparado imediatamente antes de cada experimento, de acordo com o trabalho realizado por Nishijima et al. (2014), sendo solubilizado em solução de Tween 80 1\% e diluído em solução salina livre de pirógenos a 0,9\%. O Citral era administrado por via oral (v.o.) na dose de $100 \mathrm{mg} / \mathrm{kg}$ de peso corporal (EMÍLIO-SILVA et al., 2017). 


\subsection{LPS}

O lipopolissacarídeo (LPS) (obtido a partir de E. Coli, sorotipo 0111: B4, Sigma, St. Louis, MO, EUA) foi solubilizado e diluído em salina estéril livre de pirógenos à concentração final de $3 \mathrm{mg} / \mathrm{ml}$. A dose de LPS utilizada, com base em trabalhos anteriores (GIUSTI-PAIVA et al., 2002; SAIA et al., 2013), foi de $1,5 \mathrm{mg} / \mathrm{kg}$ para indução do choque endotoxêmico, por via endovenosa.

\subsection{Grupos}

Os animais foram separados em quatro grupos experimentais, sendo eles:

a) Grupo TLPS: Tween $80(25 \mathrm{ml} / \mathrm{kg})+\operatorname{LPS}(1,5 \mathrm{mg} / \mathrm{kg})$

Composto por animais que receberam administração via oral de veículo e após 30 minutos a administração endovenosa de LPS.

b) Grupo TSAL: Tween $80(25 \mathrm{ml} / \mathrm{kg})+$ Salina $0,9 \%$

Composto por animais que receberam administração via oral de veículo e após 30 minutos a administração endovenosa de salina livre de pirógenos a $0,9 \%$.

c) Grupo CLPS: Citral (100 mg/kg) + LPS (1,5 mg/kg)

Composto por animais que receberam administração via oral de citral e após 30 minutos a administração endovenosa de LPS.

d) Grupo CSAL: Citral (100 mg/kg) + Salina 0,9\%

Composto por animais que receberam administração via oral de citral e após 30 minutos a administração endovenosa de salina livre de pirógenos a 0,9\%. 


\subsection{Procedimentos Cirúrgicos}

Para realização dos procedimentos cirúrgicos descritos a seguir os animais foram anestesiados com a mistura de Cloridrato de Cetamina 10\% (Syntec do Brasil Ltda.) e Cloridrato de Xilazina 2\% (Rhobifarma ind. Farmacêutica Ltda.) nas doses 100 e 10 mg/kg, respectivamente, por via intraperitoneal. Era feita a tricotomia dos campos cirúrgicos e limpeza com solução antisséptica.

\subsubsection{Implante de cápsula de temperatura datalogger}

Após o aprofundamento da anestesia do animal, foi inserida uma cápsula de temperatura datalogger (SubCue, Calgary, AB, Canadá) na cavidade peritoneal através de uma laparotomia medial para os registros da temperatura corporal (Tc). A camada muscular era então suturada com fio de algodão e o corte da pele fechado com grampos de sutura. Previamente ao implante o datalogger era programado para gravar os valores de temperatura a cada 5 minutos iniciando-se no dia do registro e mantido em solução antisséptica. Antes de ser inserido na cavidade peritoneal do animal o datalloger era lavado com salina $0,9 \%$ livre de pirógenos.

\subsubsection{Implante de cânula arterial e venosa}

Para o registro de pressão arterial pulsátil (PAP) e administração de LPS i.v. os animais pertencentes ao delineamento experimental 1 (descrito nos itens seguintes) passaram por outro procedimento cirúrgico, ainda sob efeito do anestésico administrado para implante do datalloger. $\mathrm{O}$ animal era submetido a uma pequena incisão na região inguinal, em direção ao feixe vásculo-nervoso para a introdução de cânulas de polietileno [confeccionadas com tubos de polietileno PE-10 com diâmetro interno de 0,01mm soldadas a tubos PE-50 com diâmetro interno de 0,05mm - (Intramedic $®$, Becton Dickinson and Co., Sparks, MD, EUA)] na luz da artéria femoral, em direção à aorta abdominal e na luz da veia femoral esquerda. As 
extremidades de menor calibre, com comprimentos de $5 \mathrm{~cm}$ para a artéria, e $3 \mathrm{~cm}$ para a veia, eram inseridas completamente na luz dos vasos correspondentes, e fixadas aos mesmos com linha de sutura. Após a introdução das extremidades menores nos vasos, as extremidades PE50, com comprimento ajustado ao tamanho do animal, eram transpassadas subcutaneamente utilizando-se um trocáter metálico, exteriorizadas no dorso e fixadas na pele com linha de sutura. Posteriormente, no momento do registro, a extremidade exteriorizada da cânula arterial permitia o acesso à PAP e a extremidade da cânula venosa a administração de LPS ou salina. Antes do implante, as cânulas eram preenchidas com salina livre de pirógenos 0,9\% heparinizada $(50 \mathrm{u} / \mathrm{ml})$ e fechadas em sua extremidade mais calibrosa com pinos de aço inoxidável para não ocorrer extravasamento de sangue até o momento do registro.

Os animais pertencentes ao delineamento experimental 2 passaram somente pela cirurgia de canulação da veia femoral, sem inserção de datalloger e registro de pressão arterial.

\subsection{Registro das variáveis cardiovasculares e temperatura corporal}

Após a cirurgia cada animal era mantido em sua caixa de manutenção forrada com maravalha numa sala com temperatura controlada $\left(23^{\circ} \mathrm{C}\right)$, onde o registro dos parâmetros cardiovasculares foi realizado.

\subsubsection{Registro dos parâmetros cardiovasculares}

Após recuperação de $24 \mathrm{~h}$ dos procedimentos cirúrgicos a extremidade exteriorizada da cânula arterial implantada no animal era conectada a um transdutor de pressão (MLT 0699, ADInstruments, Bella Vista, Australia) acoplado a um amplificador (Bridge Amp, FE2211861, ADInstruments) conectado a um sistema registro (Powerlab 8/35, PL35080562, ADInstruments) para o registro da PAP. A aquisição dos dados foi obtida por meio de software correspondente ao sistema de registro (Lab Chart Pro v. 7.3.1, Ad Instruments) com a frequência amostral de 1000 Hz. A Pressão Arterial Média (PAM) era calculada a partir da 
média do sinal da PAP em tempo real pelo software e a Frequência Cardíaca (FC) obtida através de biotacômetro, a partir do sinal de PAP. Os dados eram coletados após um período de registro estável.

\subsubsection{Registro da temperatura corporal}

A Tc foi registrada em intervalos de 5 minutos durante todo o experimento ( $1 \mathrm{~h}$ antes e 5 h depois da administração de LPS). A média dos valores de Tc registrados durante 30 minutos antes da administração do veículo ou citral v.o. foi calculada para a determinação da Tc inicial (basal). Os valores de Tc após a administração de LPS foram calculados como delta em relação ao valor basal para construção da curva de resposta da temperatura à endotoxina. Foi calculada então a área sob a curva de temperatura (ASC) de cada animal, e os valores médios de cada grupo expressos como Índice Térmico.

\subsection{Desenho experimental 1}

Com o objetivo de caracterizar as respostas termorregulatórias e cardiovasculares produzidas pela administração de LPS (1,5 mg/kg i.v.) em nosso modelo com prévio tratamento por via oral, e verificar se o pré-tratamento com citral prevenia tais respostas, foram realizados os implantes de datalloger e de cânulas tanto na artéria quanto na veia femoral esquerda dos animais de todos os grupos (Fig. 4).

Grupo TLPS: Tween $80(25 \mathrm{ml} / \mathrm{kg})+$ LPS $(1,5 \mathrm{mg} / \mathrm{kg})$

Grupo TSAL: Tween $80(25 \mathrm{ml} / \mathrm{kg})+$ Salina $0,9 \%$

Grupo CLPS: Citral (100 mg/kg) + LPS (1,5 mg/kg)

Grupo CSAL: Citral $(100 \mathrm{mg} / \mathrm{kg})+$ Salina $0,9 \%$

Figura 4. Grupos experimentais. 
Após os procedimentos cirúrgicos os animais eram mantidos em caixas individuais na sala de registro, com a temperatura de $23^{\circ} \mathrm{C}$. Após conectar a extensão da cânula arterial no transdutor, o animal era mantido sem manipulação por um período mínimo de 30 minutos. Em seguida, era administrado o pré-tratamento por via oral, e decorridos mais 30 minutos, o tratamento por via endovenosa, como esquematizado na Figura 5.

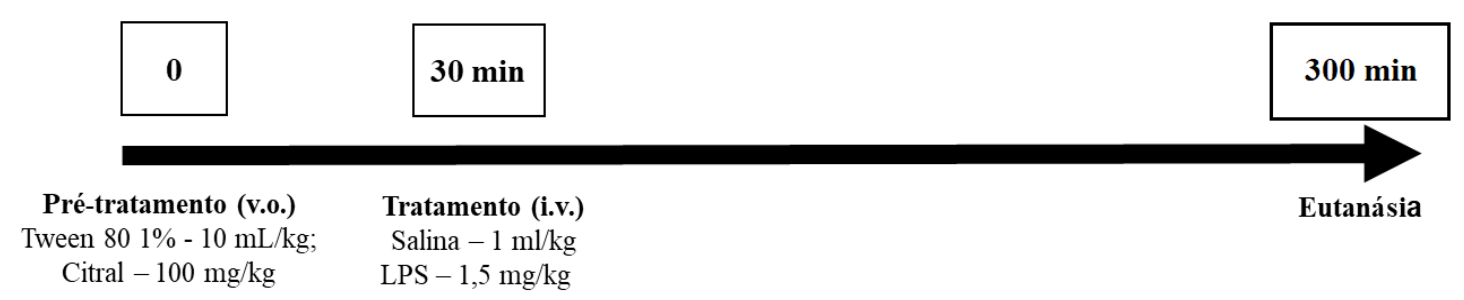

Figura 5. Sequência de procedimentos realizada no dia do registro, após a recuperação dos procedimentos cirúrgicos, com os animais do desenho experimental 1.

\subsection{Desenho experimental 2}

A fim de investigar as alterações plasmáticas promovidas pelo LPS sozinho e pelo LPS precedido da administração de citral foi realizada a cirurgia de canulação da veia femoral esquerda dos animais de todos os grupos.

Após o procedimento cirúrgico os animais eram mantidos em caixas individuais na sala de registro, com a temperatura de $23^{\circ} \mathrm{C}$. Após um período sem manipulação dos animais era administrado o pré-tratamento com veículo ou citral por via oral, e, decorridos 30 minutos, o tratamento por via endovenosa, como esquematizado na Figura 6. Aos 150 minutos da aplicação de LPS os animais eram decapitados para a coleta do cérebro e sangue.

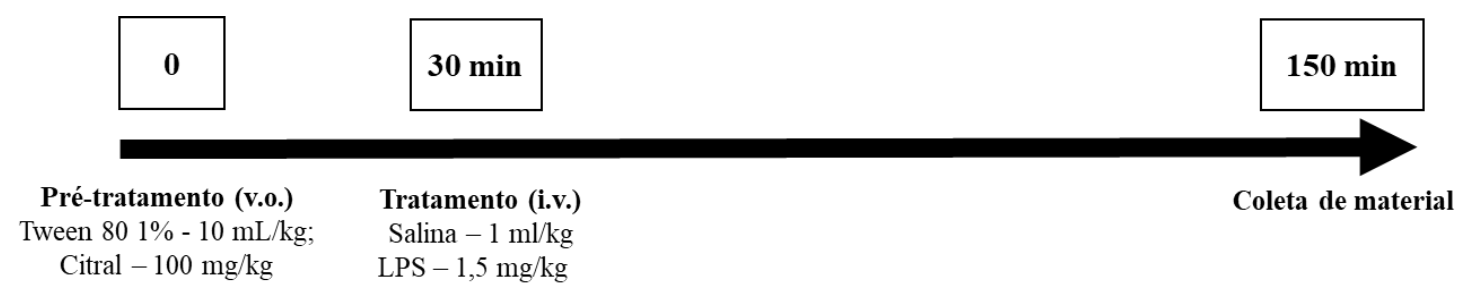

Figura 6. Sequência de procedimentos realizada para a coleta de plasma e POA, após a recuperação dos procedimentos cirúrgicos, com os animais do desenho experimental 2. 


\subsection{Processamento dos materiais coletados}

Imediatamente após a decapitação dos animais, o sangue foi coletado em tubos de vidro de $4 \mathrm{ml}$ contendo K3EDTA (ácido etilenodiamino tetra-acético tripotássico) e mantidos em gelo. As amostras foram centrifugadas a $3000 \mathrm{G}$, por $20 \mathrm{~min}$ a $4^{\circ} \mathrm{C}$ para obtenção do plasma. O plasma foi estocado em alíquotas separadas por analito a $-80^{\circ} \mathrm{C}$ até o momento das dosagens de IL-6, nitrito/nitrato, corticosterona e $\mathrm{PGE}_{2}$, sendo que na alíquota para dosagem de $\mathrm{PGE}_{2}$ foi adicionada indometacina para impedir sua formação ex vivo, como indicado pelo fabricante.

Além do sangue, o cérebro foi coletado e imediatamente congelado por imersão em isopentano resfriado por gelo seco e armazenado a $-80^{\circ} \mathrm{C}$ até o momento do corte em criostato. O cérebro era cortado a partir de sua extremidade caudal até o plano onde se inicia a POA, de acordo com as coordenadas estereotáxicas do cérebro de rato (PAXINOS; WATSON, 2007) e então amostras bilaterais dessa área (localizada nas bordas laterais do terceiro ventrículo acima do quiasma óptico - Figura 7) foram retiradas com um pino de punção cilíndrico de $0,9 \mathrm{~mm}$ de diâmetro interno em três cortes de $500 \mu \mathrm{m}$ de espessura e armazenadas em eppendorf de 1,5 ml. Foi adicionado aos eppendorfs tampão de ELISA contendo indometacina e as amostras foram homogeinizadas sobre o gelo utilizando um processador ultrassônico (Virtis, Gardiner, NY, EUA).

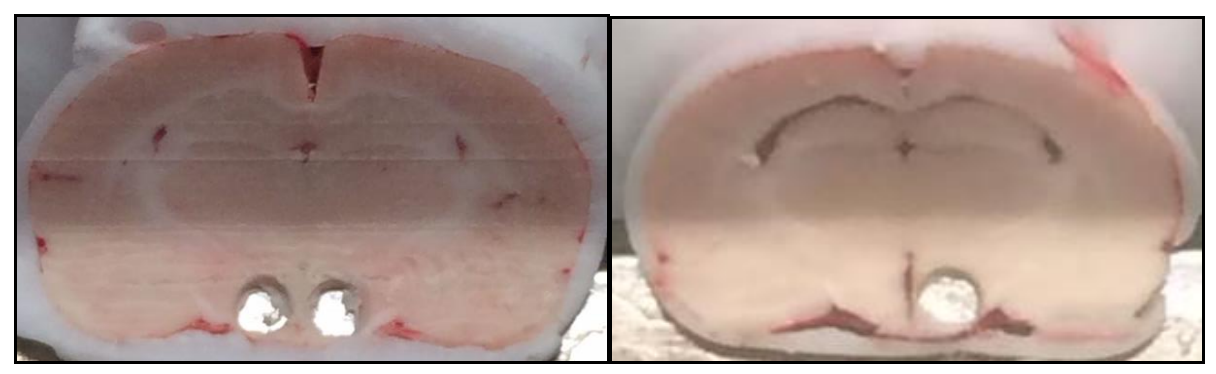

Figura 7. A imagem à esquerda mostra o plano onde foi retirada a primeira fatia de $500 \mu \mathrm{m}$ e a imagem da direita o plano onde foi retirada a última fatia.

\subsection{Dosagem dos produtos de oxidação do Óxido Nítrico (Nitrito/Nitrato - NOx)}

Alíquotas de $50 \mu \mathrm{l}$ de amostra do plasma foram desproteinizadas por precipitação utilizando $200 \mu \mathrm{l}$ de etanol $100 \%$ mantido a $4^{\circ} \mathrm{C}$, seguido de agitação e incubação por 30 minutos em freezer $\left(-20^{\circ} \mathrm{C}\right)$. Após a centrifugação $\left(4.000 \mathrm{G}, 10 \mathrm{~min}, 25^{\circ} \mathrm{C}\right)$ o protocolo de 
dosagem foi realizado como descrito a seguir. Foi utilizada a técnica de quimioluminescência NO/ozônio utilizando-se o analisador Sievers® Nitric Oxide Analyzer 280 (GE Analytical Instruments, Boulder, CO. USA). O volume de $5 \mu \mathrm{l}$ de amostra foi injetado na câmara de reação do analisador contendo o agente redutor $0,8 \%$ de cloreto de vanádio em $1 \mathrm{~N}$ de $\mathrm{HCl}$ à $95^{\circ} \mathrm{C}$ (para determinação de nitrato) ou com o agente redutor $1 \%$ de $\mathrm{Nal}$ em ácido acético (para determinação de nitrito). O conteúdo de proteína das amostras foi analisado pelo método de Lowry (Bio-Rad, EUA) e os resultados foram normalizados pela concentração proteica e expressos como $\mu \mathrm{g} / \mathrm{ml}$.

\subsection{Dosagem de Interleucina-6}

A dosagem dessa citocina foi realizada por meio de KIT de ELISA Rat IL-6 DuoSet da R\&D Systems (Cat. No. DY506), conforme orientação disponibilizada pelo manual do fabricante.

\subsection{Dosagem de Prostaglandina $E_{2}$ plasmática e na POA}

Realizada por meio de KIT de Prostaglandin $E_{2}$ ELISA - Monoclonal da Cayman (No. 514010), conforme orientação disponibilizada pelo manual do fabricante.

\subsection{Dosagem de Prostaglandina $D_{2}$ na POA}

Realizada por meio de KIT de Prostaglandin $\mathrm{D}_{2}$ - MOX ELISA da Cayman Chemical (No. 512011), conforme orientação disponibilizada pelo manual do fabricante.

\subsection{Dosagem de Corticosterona}

Os níveis plasmáticos de corticosterona foram determinados após sua extração do plasma com a adição de etanol 100\%, centrifugação e remoção do precipitado. As amostras foram transferidas de tubo para a completa evaporação do etanol. Em seguida, foi adicionado tampão Tris-gelatina $0,05 \mathrm{M}$ com $\mathrm{pH}$ de 8,0 e o anticorpo primário anti-corticosterona (Corticosterone Antiserum Developed in rabbit - ref. C8784-100TST, Sigma). Foi adicionada 
corticosterona triciada e procedida a incubação por $24 \mathrm{~h}$ em sala com temperatura de $24^{\circ} \mathrm{C}$. Após a incubação, foi adicionado carvão ativado nas amostras seguindo de agitação e incubação em gelo. As amostras foram transferidas para tubos de cintilação nos quais foi adicionado o líquido de cintilação, e agitados antes de serem colocados no contador beta. Os dados obtidos foram analisados com o software Multicalc. Esta análise foi realizada no Laboratório de Neuroendocrinologia da Reprodução Feminina da Faculdade de Odontologia de Ribeirão Preto da Universidade de São Paulo.

\subsection{Análise estatística}

Os resultados foram expressos como médias \pm Erro Padrão da Média (EPM). Para análise estatística dos resultados com duas variáveis (tempo após o tratamento e tratamento) foi empregado o teste de análise bidirecional de variância (two-way ANOVA), seguido do teste post hoc de Newman-Keuls. Para os resultados que não sofriam influência do tempo (ASC da temperatura corporal) foi empregado o teste de análise unidirecional (one-way ANOVA), seguido do teste post hoc de Newman-Keuls. O nível de significância adotado foi de $5 \%(\mathrm{p}<0,05)$. 


\section{4 - RESULTADOS}

\subsection{Caracterização do modelo}

Inicialmente, a eficiência do LPS em nosso modelo de endotoxemia foi comprovada pela queda na pressão arterial média (PAM) observada no grupo pré-tratado com veículo e tratado com LPS na dose de $1,5 \mathrm{mg} / \mathrm{kg}$ (TLPS) o que não foi observado no grupo pré tratado com veículo e tratado com salina livre de pirógenos (TSAL). Os valores de PAM em relação ao tempo destes dois grupos estão expressos como média \pm EPM na Figura 8.

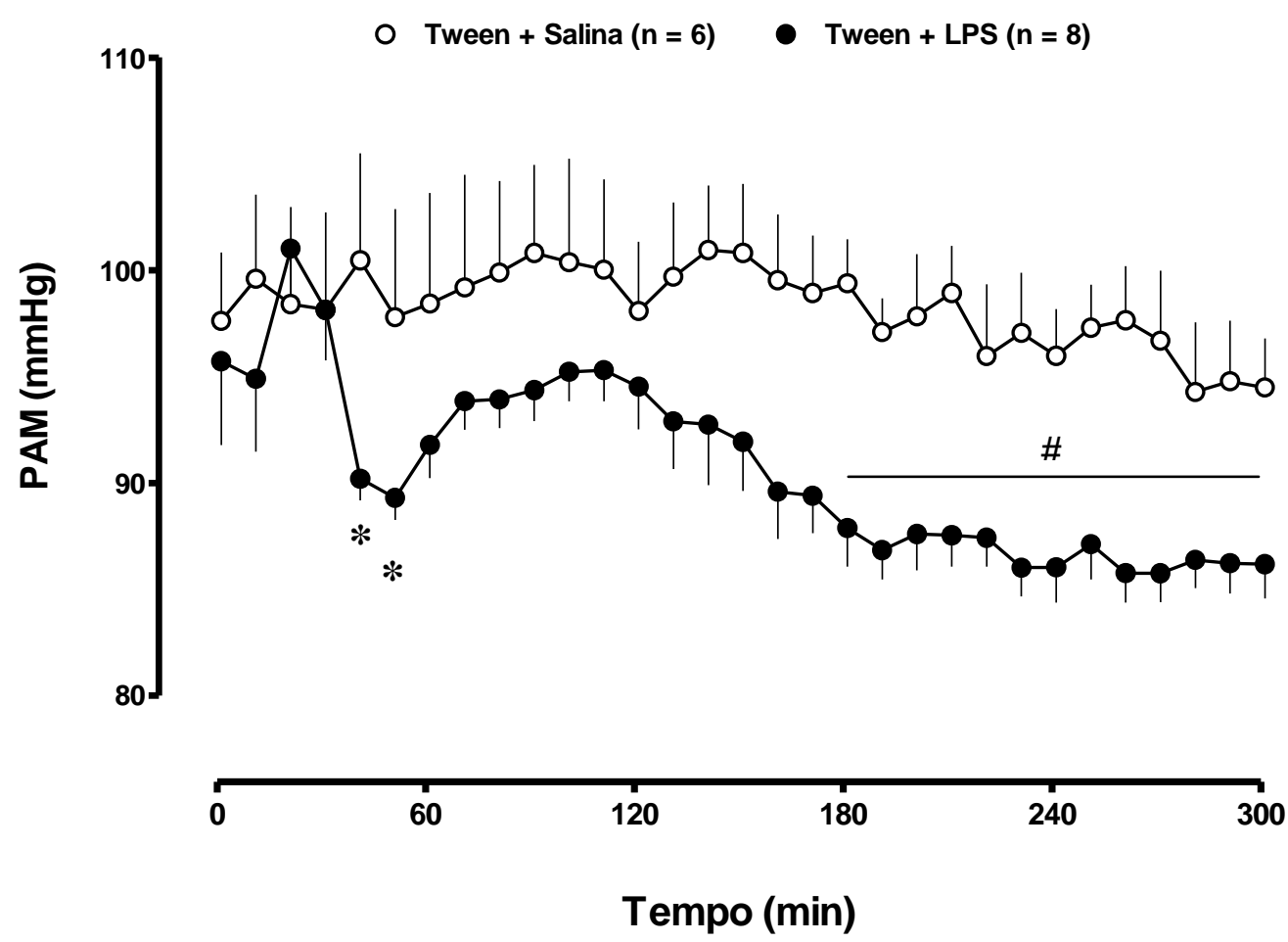

Figura 8. Evolução temporal da pressão arterial média (PAM) de ratos controle tratados com salina (círculos brancos) ou tratados com LPS (círculos pretos). Apresentam-se as médias \pm EPM dos valores PAM dos animais dos grupos TLPS e TSAL em relação ao tempo avaliadas por análise bidirecional de variância (two-way ANOVA), seguido pelo teste de Newman-Keuls (Grupo TLPS: ${ }^{*} \mathrm{p}<0,05$ em relação ao tempo 30; \# p < 0,05 em relação ao tempo 0).

Além da PAM, a frequência cardíaca (FC) sofreu clara alteração, como demonstrado na Figura 9. Houve um drástico aumento na FC logo após os primeiros 10 minutos da 
administração do LPS nos animais do grupo TLPS, equanto no grupo TSAL essa alteração não foi observada.

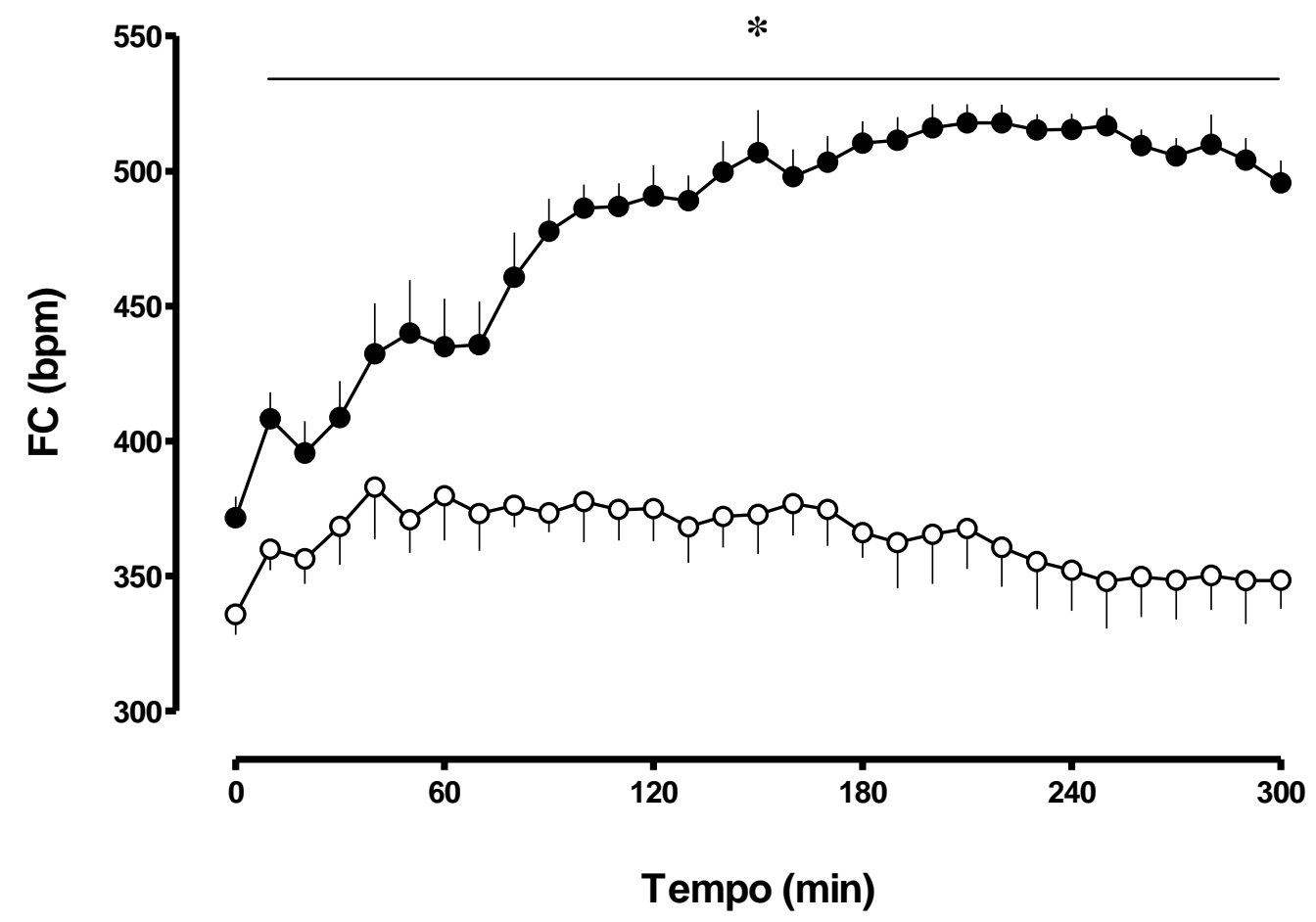

Figura 9. Evolução temporal da frequência cardíaca (FC) de ratos controle tratados com salina (círculos brancos) ou tratados com LPS (círculos pretos). Apresentam-se as médias \pm EPM dos valores de FC dos animais dos grupos TLPS e TSAL em relação ao tempo avaliadas por análise bidirecional de variância (two-way ANOVA), seguido pelo teste de Newman-Keuls (Grupo TLPS: *p < 0,05 em relação ao tempo 0).

\subsection{Influência do citral na pressão arterial, frequência cardíaca e produção de óxido nítrico}

Na Figura 10 estão expressas as médias dos valores de PAM e FC de todos os grupos experimentais. Como podemos observar, o citral adiou a queda acentuada da pressão arterial, mas não foi capaz de prevenir a magnitude dessa resposta provocada pelo LPS. No painel inferior, o perfil temporal da FC demonstra que esta variável também não foi diferente entre os grupos tratados com citral e veículo, sendo que ambos apresentaram aumento acentuado nesse parâmetro a partir de 10 minutos após a administração da endotoxina. 

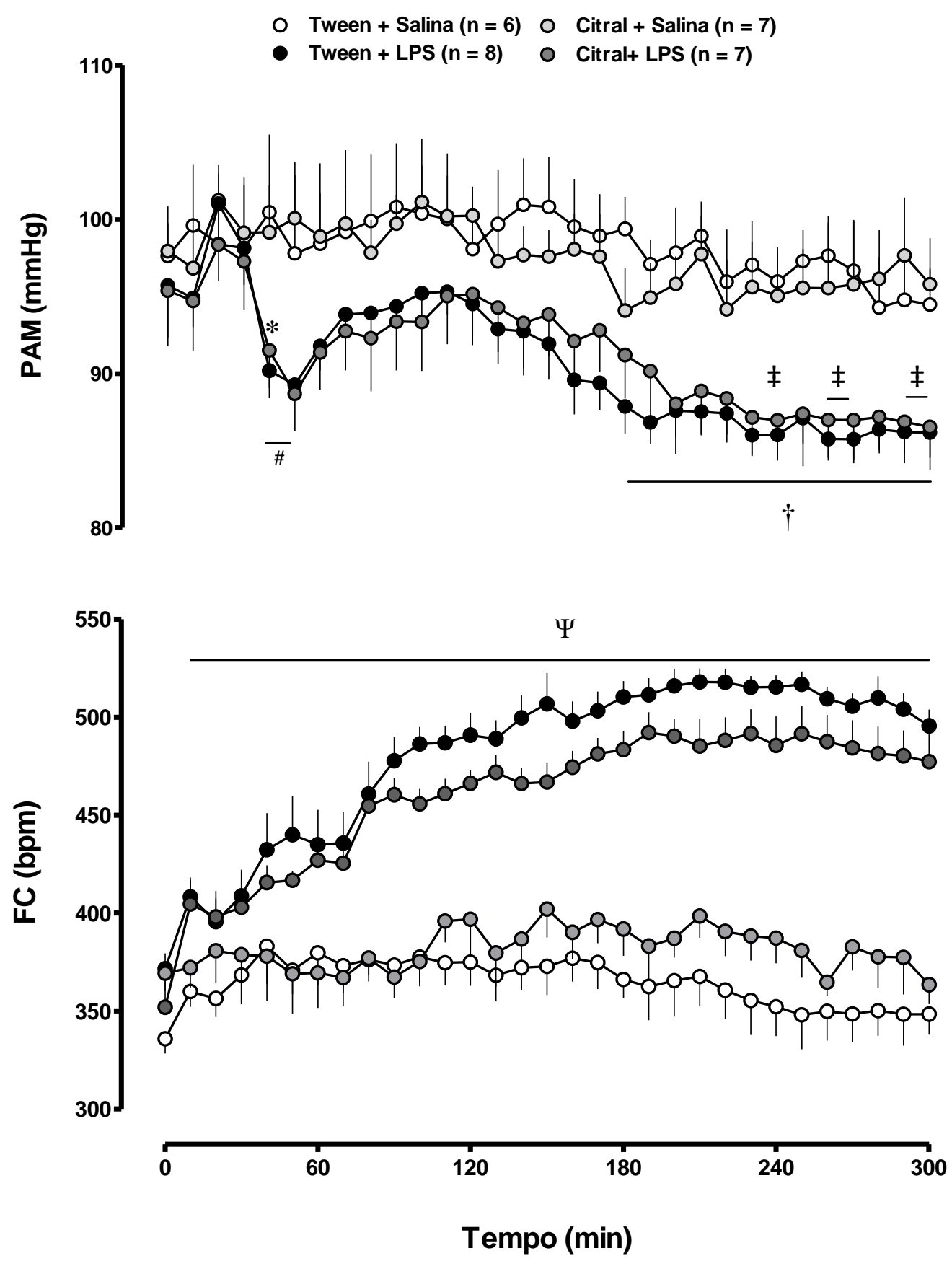

Figura 10. Evolução temporal da PAM e FC de ratos controle tratados com salina (círculos brancos) ou tratados com LPS (círculos pretos) e ratos pré-tratados com citral e tratados com salina (círculos cinza claro) ou LPS (círculos cinza escuro). Apresentam-se as médias \pm EPM dos valores de pressão arterial média (painel superior) e frequência cardíaca (painel inferior) dos animais dos grupos TLPS, CLPS, TSAL e CSAL em relação ao tempo avaliadas por análise bidirecional de variância (two-way ANOVA), seguido pelo teste de Newman-Keuls (Grupo TLPS: \# p < 0,05 em relação ao tempo 30; $\uparrow$ em relação ao tempo 0. Grupo CLPS: * p < 0,05 em relação ao tempo 30; $\$$ em relação ao tempo 0 . Grupos TLSP e CLPS: $\Psi$ p $<0,05$ em relação ao tempo 0 ). Os resultados do grupo TPLS e TSAL são os mesmos demonstrados nas Figuras 1 e 2. 
Quando avaliamos a produção de NO por meio dos produtos de sua oxidação, nitrito e nitrato (NOx), podemos verificar na Figura 11 que nos grupos tratados com LPS (TLPS 112,7 $\pm 8,61$ e CLPS $138,2 \pm 11,85 \mu \mathrm{M}$ ) a produção desse mediador gasoso foi maior em relação aos grupos controle (TSAL 39,53 \pm 3,08 e CSAL 58,62 \pm 6,42 $\mu \mathrm{M}$ ), porém não foi diferente entre si.

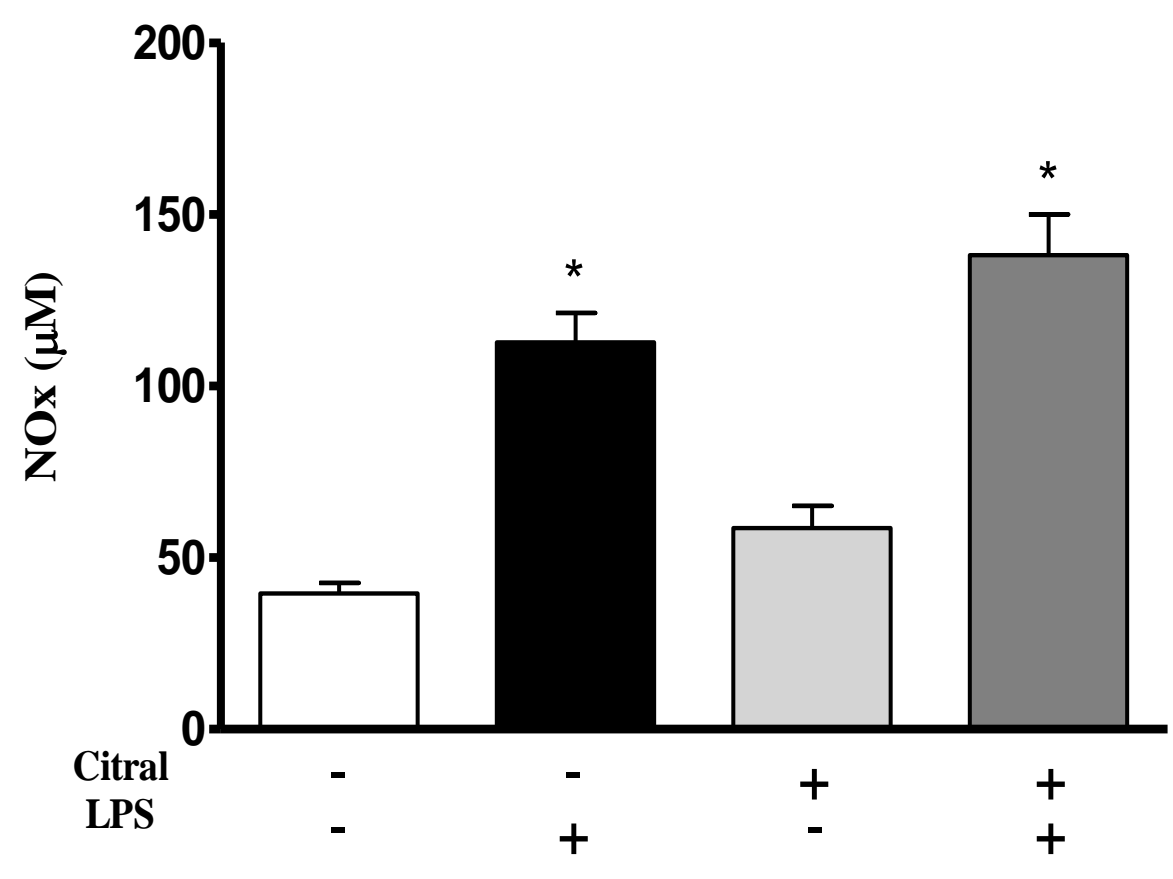

Figura 11. Avaliação indireta da produção de NO, por meio da dosagem de nitrito e nitrato plasmático (NOx). Apresentam-se as médias \pm EPM da concentração plasmática de NOx dos animais dos grupos TLPS, CLPS, TSAL e CSAL avaliadas aos 150 minutos após o tratamento com LPS ou salina livre de pirógenos $0,9 \%$. As diferenças entre os grupos foram verificadas por análise de variância unidirecional (two-way ANOVA), seguido pelo teste de Newman-Keuls $(* \mathrm{p}<0,0001$; em relação aos grupos TSAL e CSAL).

\subsection{Influência do citral na regulação da temperatura corporal}

O perfil das alterações termorregulatórias observadas nos grupos estudados está apresentado no painel A da Figura 12. A análise da área sob a curva (ASC), exposta no painel B da Figura 12 é expressa como índice térmico, e nos mostra que no período inicial, onde esperávamos que os animais do grupo TLPS desenvolvessem anapirexia, nós não observamos essa resposta (Fig. 5B superior). No entanto, como esperado, num segundo momento os 
animais dos grupos TLPS e CLPS desenvolveram febre (Fig. 5B inferior). Como podemos observar a resposta febril não foi atenuada pelo pré-tratamento com citral.

A

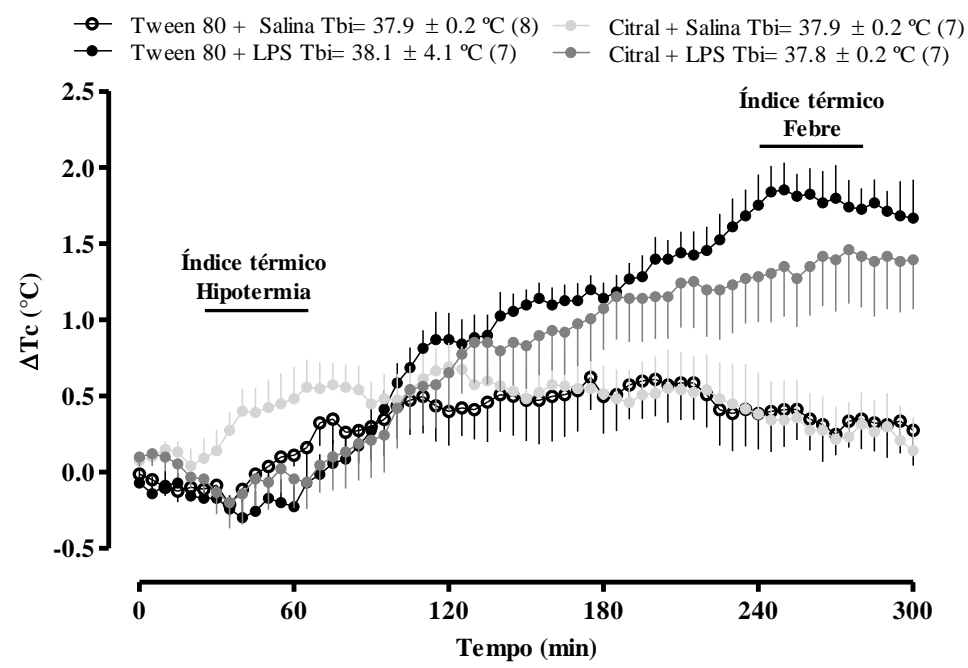

B

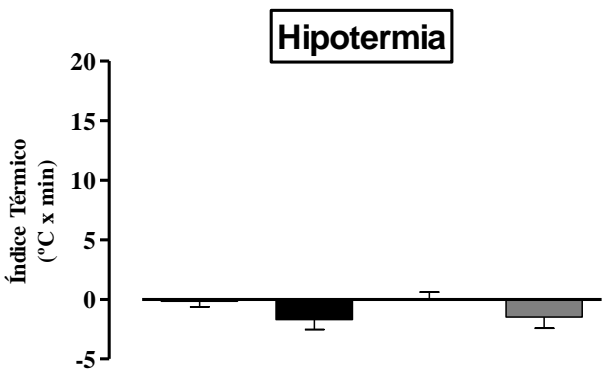

Febre

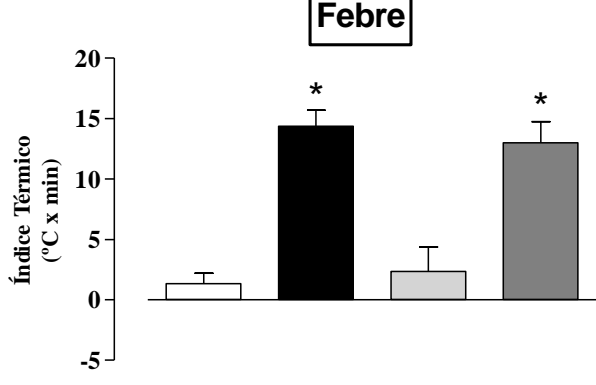

$\begin{array}{lllll}\text { Citral } & - & - & + & + \\ \text { LPS } & - & + & - & +\end{array}$

Figura 12. A. Evolução temporal da variação de temperatura corporal de ratos controle tratados com salina (círculos brancos) ou tratados com LPS (círculos pretos) e ratos pré-tratados com citral e tratados com salina (círculos cinza claro) ou LPS (círculos cinza escuro). B Painel superior: área sob a curva de temperatura corporal avaliada entre os minutos 25-65; Painel inferior: área sob a curva de temperatura corporal avaliada entre os minutos 240 e 280 . As diferenças entre os grupos foram verificadas por análise de variância unidirecional (two-way ANOVA), seguido pelo teste de NewmanKeuls (* p < 0,0001; em relação aos grupos TSAL e CSAL).

\subsection{Análise dos mediadores plasmáticos da inflamação}

Por meio da dosagem de IL-6 e $\mathrm{PGE}_{2}$ plasmáticas pudemos analisar a magnitude da resposta inflamatória ao LPS. Ao observarmos a Figura 13 podemos identificar o aumento na concentração plasmática de IL-6 nos grupos de ambos os pré-tratamentos e tratados com LPS (TLPS $1449 \pm 252,2$ e CLPS $1878 \pm 268,0$ pg/ml) em relação aos grupos controle (TSAL 594,2 $\pm 42,8$ e CSAL $639,8 \pm 92,92 \mathrm{pg} / \mathrm{ml}$ ). Os grupos de um mesmo tratamento não foram diferentes entre si. 


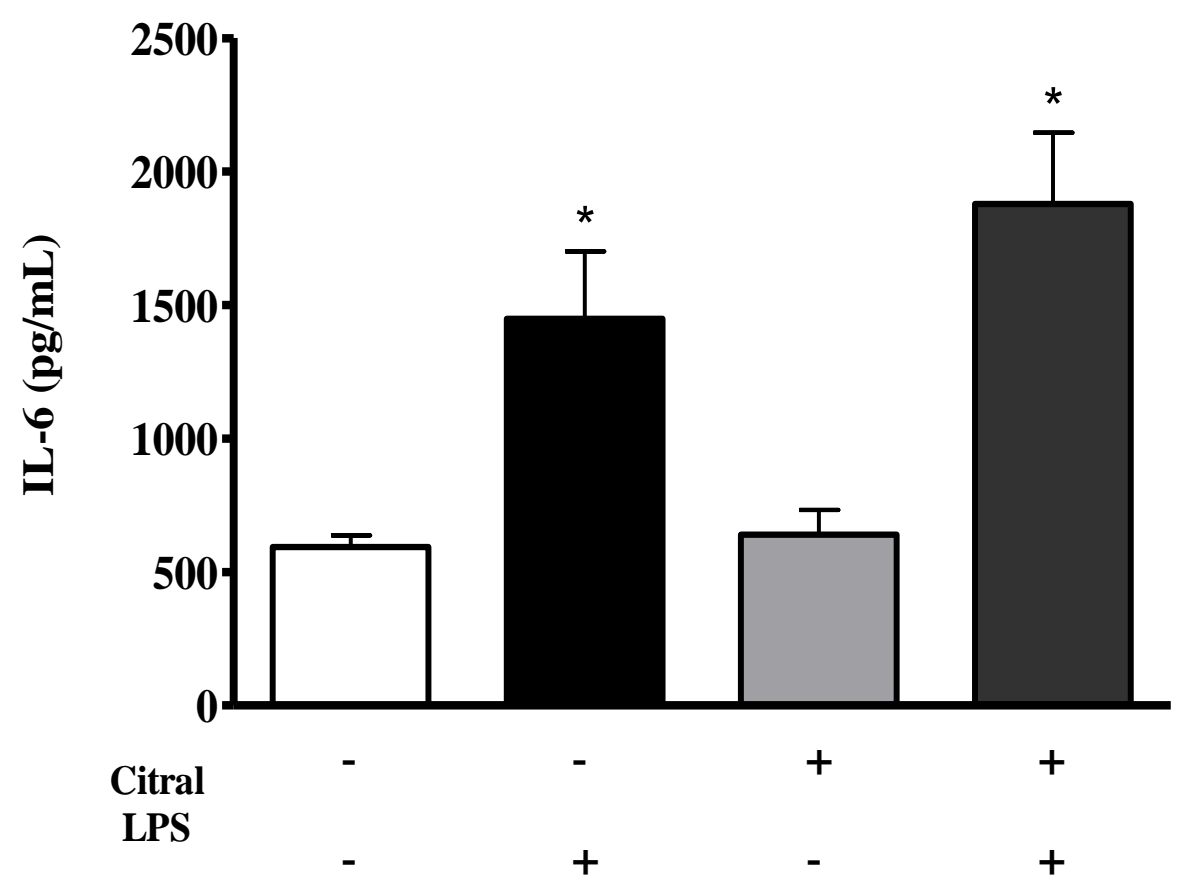

Figura 13. Concentrações plasmáticas de interleucina 6. Apresentam-se as médias \pm EPM da concentração plasmática de IL-6 dos animais dos grupos TLPS, CLPS, TSAL e CSAL avaliadas aos 150 minutos após o tratamento com LPS ou salina livre de pirógenos $0,9 \%$. As diferenças entre os grupos foram verificadas por análise de variância unidirecional (two-way ANOVA), seguido pelo teste de Newman-Keuls (* $p<0,05$; em relação aos grupos TSAL e CSAL).

Foi observado um grande aumento na produção de PGE $_{2}$ do grupo TLPS quando comparado aos grupos tratados com salina (TLPS 1085,0 \pm 442,4 vs TSAL 42,5 \pm 17,8 e CSAL 137,9 $\pm 39,1 \mathrm{pg} / \mathrm{ml})$. O grupo CLPS $(646,6 \pm 224,8 \mathrm{pg} / \mathrm{ml})$ não foi diferente estatisticamente em relação aos grupos tratados com salina nem em relação ao grupo pré tratado apenas com veículo. A concentração de $\mathrm{PGE}_{2}$ plasmática em todos os grupos é apresentada como média \pm EMP na Figura 14. 


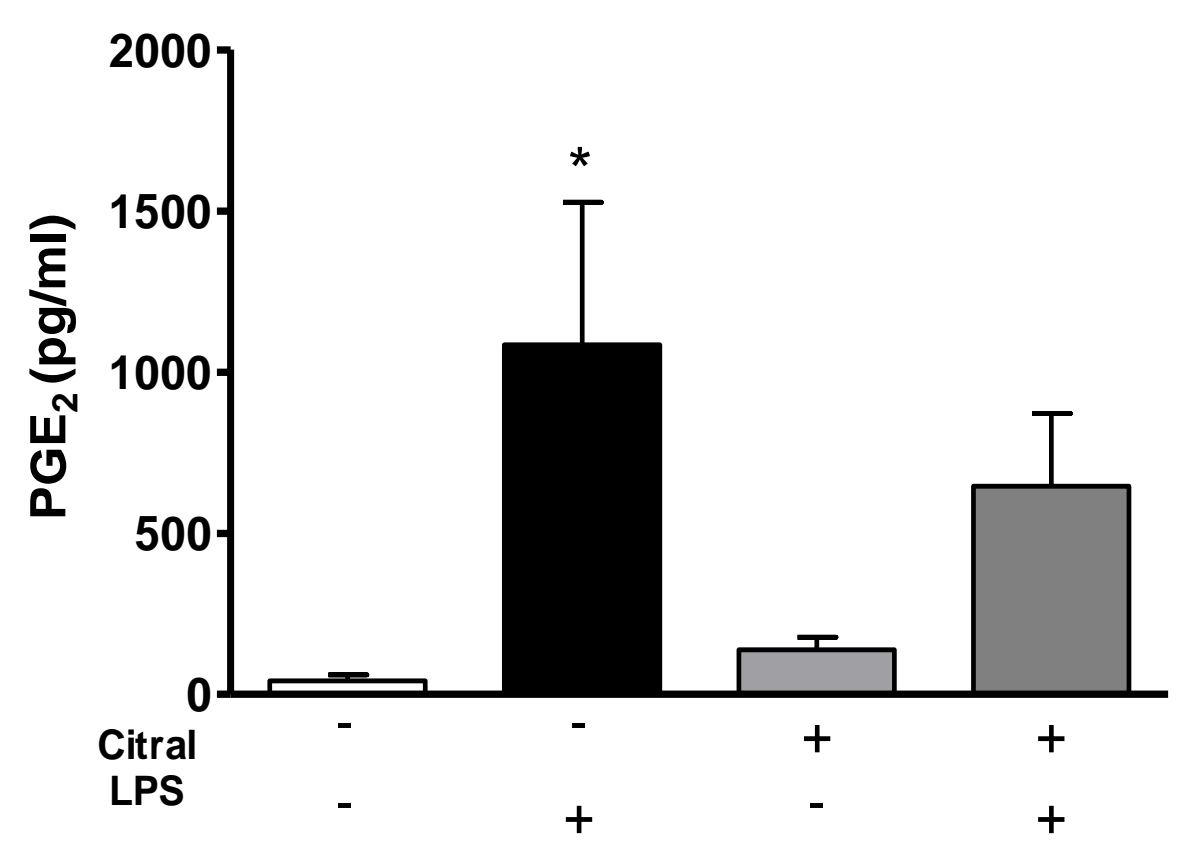

Figura 14. Concentrações plasmáticas de $\mathrm{PGE}_{2}$. Apresentam-se as médias $\pm \mathrm{EMP}$ dos animais dos grupos TLPS, CLPS, TSAL e CSAL avaliadas aos 150 minutos após o tratamento com LPS ou salina livre de pirógenos $0,9 \%$. As diferenças entre os grupos foram verificadas por análise de variância unidirecional (two-way ANOVA), seguido pelo teste de Newman-Keuls (* $p<0,05$; em relação aos grupos TSAL e CSAL).

As concentrações plasmáticas de corticosterona foram aumentadas com a administração de LPS em relação aos controles como esperado, porém o citral não influenciou esse parâmetro, como demonstrado na Figura 15. Os grupos dentro de cada tratamento não foram diferentes entre si (TSAL 55,6 \pm 5,9 e CSAL 81,7 \pm 11,3; TLPS 127,6 \pm 8,4 e CLPS $125,5 \pm 9,9 \mathrm{ng} / \mathrm{ml})$. 


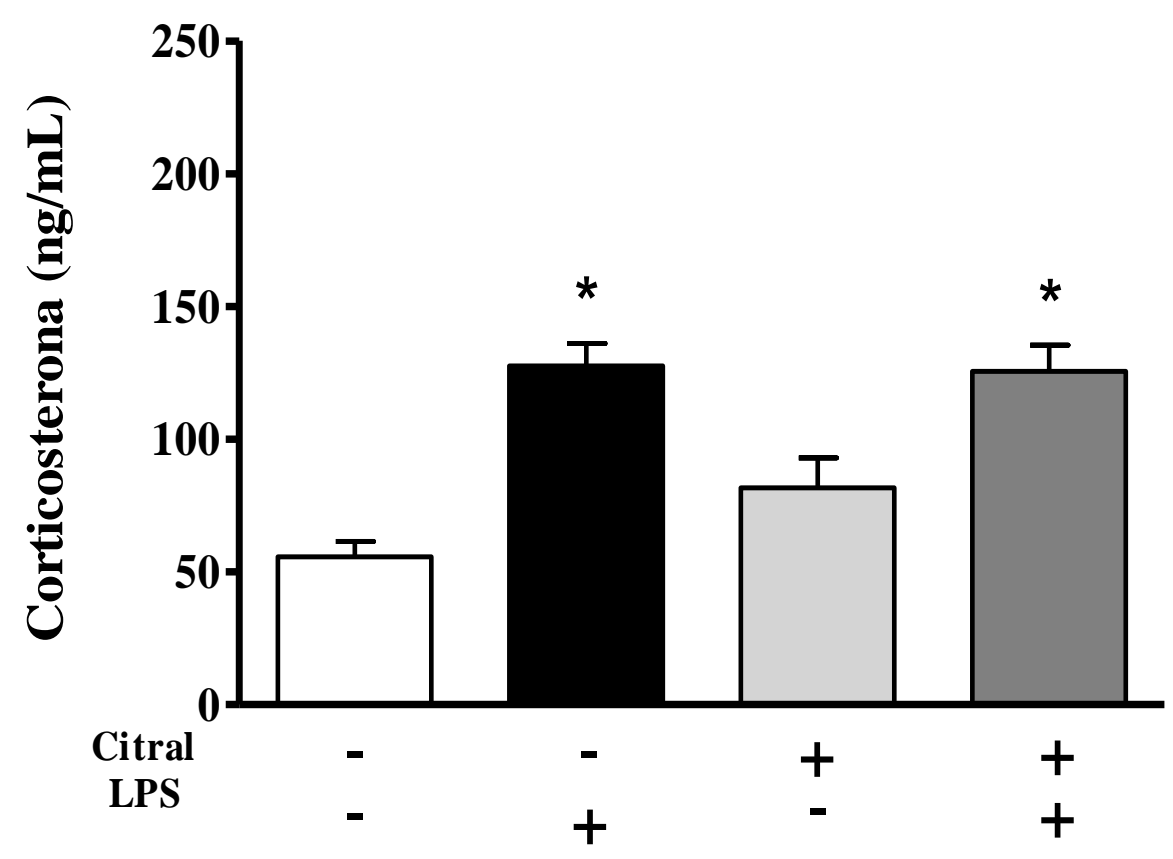

Figura 15. Concentrações plasmáticas de corticosterona. Apresentam-se as médias \pm EPM da concentração plasmática de corticosterona dos animais dos grupos TLPS, CLPS, TSAL e CSAL avaliadas aos 150 minutos após o tratamento com LPS ou salina livre de pirógenos 0,9\%. As diferenças entre os grupos foram verificadas por análise de variância unidirecional (two-way ANOVA), seguido pelo teste de Newman-Keuls (* $\mathrm{p}<0,05$; em relação aos grupos TSAL e CSAL).

\subsection{Análise dos mediadores inflamatórios na POA}

Na POA o LPS promoveu aumento na produção de $\mathrm{PGE}_{2}$, como demonstrado nos resultados do grupo TLPS $(0,29 \pm 0,1$ vs TSAL $0,004 \pm 0,001$ e CSAL $0,05 \pm 0,01)$. O grupo CLPS $(0,19 \pm 0,06)$ foi diferente apenas do grupo TSAL. Estes resultados estão expressos como média \pm EPM no painel superior da Figura 16.

Diferentemente da $\mathrm{PGE}_{2}$ a $\mathrm{PGD}_{2}$ teve sua produção alterada no grupo pré tratado com citral em relação ao grupo pré tratado com veículo (CLPS 0,25 $\pm 0,05$ vs TLPS 0,68 $\pm 0,12$ pg.mg ${ }^{-1}$ de proteína) . O grupo CLPS teve a produção de $\mathrm{PGD}_{2}$ aumentada em relação ao CSAL $\left(0,01 \pm 0,005\right.$ pg.mg ${ }^{-1}$ de proteína $)$, mas não ao TSAL $\left(0,11 \pm 0,02\right.$ pg.mg ${ }^{-1}$ de proteína). O que nos chama atenção é que este resultado é consistente com nossos achados em estudos anteriores, que demonstram uma ação anti-inflamatória do citral (v.o.) em doses bem menores de LPS, administrado por via intraperitoneal. Nosso modelo é bem mais agressivo que o modelo de febre, o que poderia influenciar o poder do citral em exercer ações protetoras contra a endotoxina, mas mesmo assim, o citral foi capaz de atenuar a produção de um dos 
mediadores inflamatórios na área de maior importância em termos de regulação da temperatura corporal.
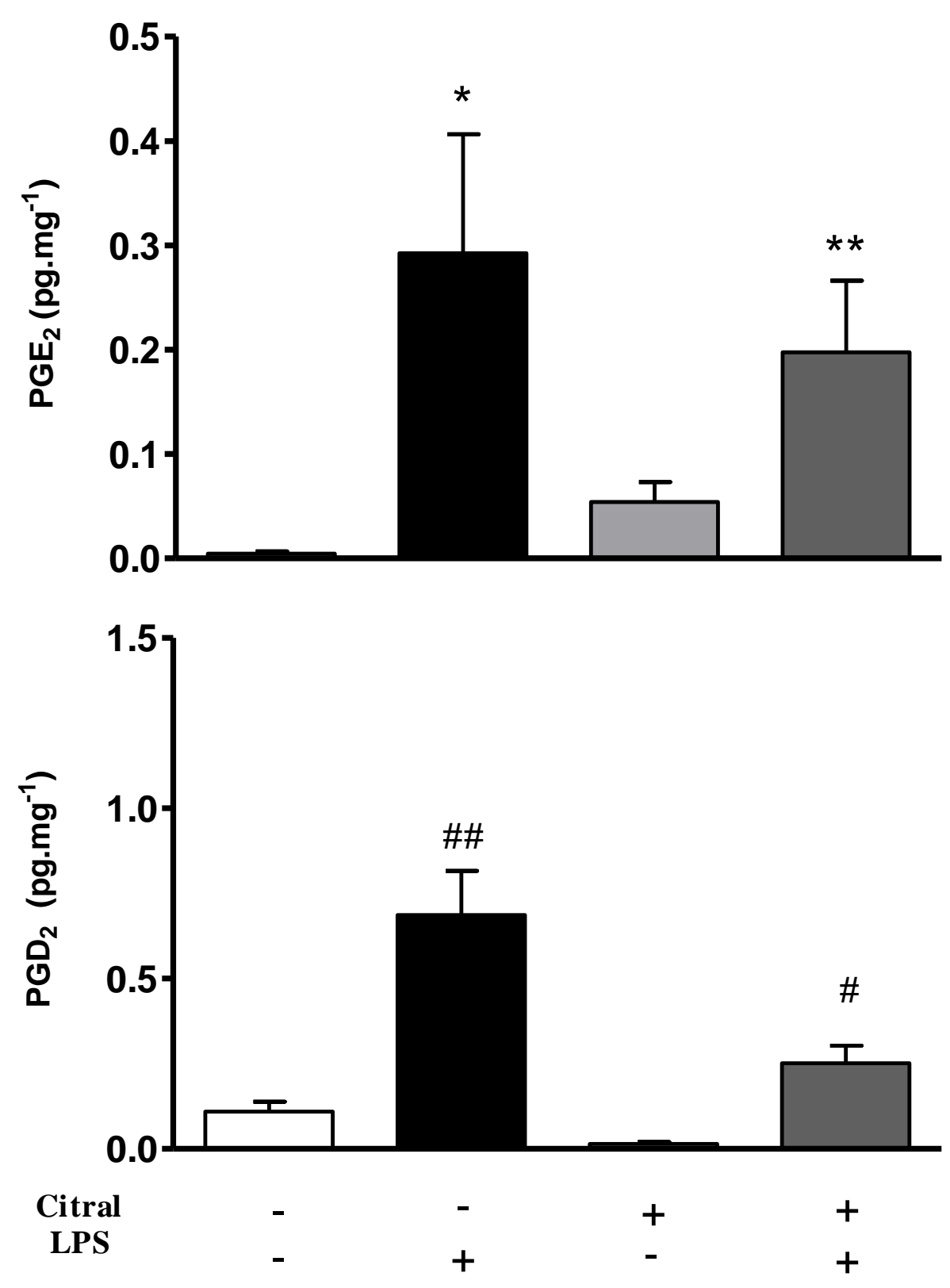

Figura 16. Concentrações de $\mathrm{PGE}_{2}$ e $\mathrm{PGD}_{2}$ na $\mathrm{POA}$. Apresentam-se as médias $\pm \mathrm{EPM}$ das concentrações de $\mathrm{PGE}_{2}$ (painel superior) e $\mathrm{PGD}_{2}$ (painel inferior) na $\mathrm{POA}$ dos animais dos grupos TLPS, CLPS, TSAL e CSAL avaliadas aos 150 minutos após o tratamento com LPS ou salina livre de pirógenos $0,9 \%$ (valores normalizados por miligrama de proteína). As diferenças entre os grupos foram verificadas por análise de variância unidirecional (two-way ANOVA), seguido pelo teste de Newman-Keuls $(* \mathrm{p}<0,05$; em relação aos grupos TSAL e CSAL; $* * p<0,05$ em relação ao grupo TSAL; \#\# $\mathrm{p}<0,0001$ em relação aos grupos TSAL, CSAL e CLPS; \#p $<0,05$ em relação ao grupo CSAL). 


\section{5 - DISCUSSÃO}

A presente dissertação traz informações inéditas a respeito do eventual efeito do citral sobre importantes e bem caracterizadas alterações observadas durante o choque endotoxêmico induzido por LPS. À exceção da $\mathrm{PGD}_{2}$, observou-se que o citral não previne nenhum dos parametros analisados. O citral tem, de fato, importante efeito anti-inflamatório em vários modelos experimentais, como febre induzida por dose relativamente baixa de LPS (EMÍLIOSILVA et al., 2017), úlceras gástricas induzidas por ainti-inflamatórios não esteroidais (NISHIJIMA et al., 2014b) e em cultura de células (SONG et al., 2016). Essa ação, porém, não se mostrou eficaz no modelo de choque endotoxêmico.

A resposta inflamatória acentuada exerce uma função essencial nos consequentes danos teciduais observados em pacientes sépticos. Ela é fundamental para reestabelecer o estado saudável dos tecidos, porém também pode ser prejudicial na presença de doenças ou outras condições em que sua magnitude é exacerbada. Em situações de trauma ou sepse, quando a resposta inflamatória é exagerada, a liberação excessiva de seus mediadores pode ser danosa a ponto de provocar falência múltipla dos órgãos e até mesmo a morte. Dado esse contexto, é crucial entendermos como a resposta inflamatória aguda é organizada e testarmos ferramentas farmacológicas para a criação/expansão de novas estratégias de tratamento.

Nosso trabalho demonstra várias evidências experimentais de que, mesmo capaz de atenuar a produção de $\mathrm{PGD}_{2}$ na $\mathrm{POA}$, o citral não é suficiente, na dose utilizada, para prevenir o organismo das alterações inflamatórias, térmicas e cardiovasculares promovidas pelo LPS em ratos, um modelo extensamente utilizado para estudo da sepse in vivo. Nós observamos que a redução na pressão arterial (Fig. 10), aumento na frequência cardíaca (Fig. 10), produção de NO (Fig. 11), a febre (Fig. 12) e a liberação de mediadores inflamatórios plasmáticos (Figs. 13 e 14) não são atenuados no choque endotoxêmico quando o citral é administrado previamente.

Os níveis plasmáticos de corticosterona aumentaram em resposta à inflamação sistêmica, achado que vai ao encontro dos observados na literatura científica, já que está relacionado aos níveis de estresse ao qual o organismo é exposto. Se o citral alterasse as respostas inflamatórias positivamente, esperaríamos um aumento na concentração de corticosterona, que não foi observado em nosso estudo (Fig. 15). Esse achado está de acordo com os 
resultados encontrados em trabalhos anteriores do laboratório, onde o citral não promoveu alteração nos níveis deste glicocorticoide (EMÍLIO-SILVA et al., 2017).

As células fagocíticas (principalmente macrófagos) são as maiores responsáveis pela produção e liberação de mediadores inflamatórios, como as citocinas. Com o desafio imune imposto pela administração de LPS em altas doses e a sua ligação aos seu receptor de reconhecimento padrão, o TLR-4, a cascata de sinalização intracelular gera estimulação da síntese de IL-1 $\beta$, IL-6 and TNF- $\alpha$, liberando esses mediadores em massa para a circulação sistêmica. Dentre outras moléculas, essas citocinas são importantes sinais desencadeadores da resposta de fase aguda elaborada pelo sistema imune. Tomando essas informações como base, nós avaliamos os níveis plasmáticos de IL-6 durante o pico da resposta febril no choque endotoxêmico. Além disso, também verificamos os níveis de $\mathrm{PGE}_{2}$ no plasma e na POA. O citral, tanto sozinho, como antes da administração de LPS não promoveu alteração nesses dois parâmetros analizados (Figs. 13, 14 e painel superior da Fig. 16). Dado que a produção de $\mathrm{PGE}_{2}$ na POA está intimamente relacionada com a sinalização responsável pela geração da febre, a sua não alteração justifica os resultados relacionados a temperatura corporal (Fig. 12).

Interessante notar que o presente estudo indica que na região hierarquicamente mais importante na regulação da temperatura corporal, apesar de não observarmos alterações na liberação de $\mathrm{PGE}_{2}$ (Fig. 16) e na temperatura corporal (Fig 12), houve redução dos níveis de $\mathrm{PGD}_{2}$, outro importante mediador da resposta térmica (Fig. 16), evidenciando a necessidade de uma investigação mais detalhada a respeito do mecanismo pelo qual essa resposta é mediada.

Esse achado é consistente com o encontrado na literatura de que a expressão da enzima COX-2 induzida por LPS é suprimida pelo citral (KATSUKAWA et al., 2010). No entanto, a diferença nos resultados de $\mathrm{PGE}_{2}$ e $\mathrm{PGD}_{2}$ sugerem que nessa situação a regulação da sua liberação é diferenciada.

Outro estudo evidencia efeito inibitório do citral sobre a produção de NO, via redução da expressão de iNOS e ativação de NFkB em células RAW 264.7 (LEE et al., 2008). No presente trabalho não foi observada redução na produção de NO, porém nosso modelo trata-se de um organismo complexo enfrentando um desafio imunológico, o que torna o cenário bastante diferente de estudos com células isoladas. 
Em conjunto nossos resultados indicam que, embora o citral exerça um efeito antiinflamatório durante a inflamação sistêmica induzida por baixas doses de LPS - um modelo bem estabelecido para o estudo da febre, esse papel é insuficiente para prevenir as respostas do sistema imune frente a um desafio de maior magnitude, o choque endotoxêmico. No entanto, permanece para ser esclarecido o efeito inibitório do citral na produção de $\mathrm{PGD}_{2}$ na POA. 


\section{6 - CONCLUSÕES}

Nosso estudo nos permite concluir que o citral, na dose de $100 \mathrm{mg} / \mathrm{kg}$, administrado por via oral 30 minutos antes da indução do choque endotoxêmico, não afeta as alterações inflamatórias, termorregulatórias e hemodinâmicas características do modelo. No entanto, outros estudos são necessários para investigar o mecanismo pelo qual este composto age reduzindo a produção de $\mathrm{PGD}_{2}$ na área pré óptica do hipotálamo. 


\section{REFERÊNCIAS}

AKIRA, S.; UEMATSU, S.; TAKEUCHI, O. Pathogen recognition and innate immunity. Cell, v. 124, n. 4, p. 783-801, 2006.

ALMEIDA, M. C.; STEINER, A. A.; BRANCO, L. G. S.; ROMANOVSKY, A. A. Coldseeking behavior as a thermoregulatory strategy in systemic inflammation. European Journal of Neuroscience, v. 23, n. 12, p. 3359-3367, jun. 2006.

BICEGO, K. C.; BARROS, R. C. H.; BRANCO, L. G. S. Physiology of temperature regulation: Comparative aspects. Comparative Biochemistry and Physiology Part A: Molecular \& Integrative Physiology, v. 147, n. 3, p. 616-639, jul. 2007.

BLATTEIS, C. M. Endotoxic fever: New concepts of its regulation suggest new approaches to its management. Pharmacology and Therapeutics, v. 111, n. 1, p. 194-223, 2006.

BLATTEIS, C. M.; LI, S.; LI, Z.; FELEDER, C.; PERLIK, V. Cytokines, PGE2 and endotoxic fever: A re-assessment. Prostaglandins and Other Lipid Mediators, v. 76, n. 14, p. 1-18, 2005.

BOULANT, J. A. NEURAL THERMAL RECEPTION AND REGULATION OF BODY TEMPERATURE. In: Physiology and Pathophysiology of Temperature Regulation. [s.1.] WORLD SCIENTIFIC, 1998. p. 93-105.

BOULANT, J. A. Role of the Preoptic-Anterior Hypothalamus in Thermoregulation and Fever. Clinical Infectious Diseases, v. 31, n. Supplement_5, p. S157-S161, 1 out. 2000.

BRANCO, L. G. S.; SORIANO, R. N.; STEINER, A. A. Gaseous Mediators in Temperature Regulation. In: Comprehensive Physiology. Hoboken, NJ, USA: John Wiley \& Sons, Inc., 2014. p. 1301-1338.

BURAS, J. A.; HOLZMANN, B.; SITKOVSKY, M. Model organisms: Animal models of sepsis: Setting the stage. Nature Reviews Drug Discovery, v. 4, n. 10, p. 854-865, 2005.

INSTITUTO LATINO-AMERICANO DE SEPSE. Sepse: um problema de saúde pública / Instituto Latino-Americano de Sepse. Brasília: Conselho Federal de Medicina, 2015.

CONDE, K. A. P.; SIlVA, E.; SILVA, C. O.; FERREIRA, E.; FREITAS, F. G. R.; 
CASTRO, I.; REA-NETO, A.; GRION, C. M. C.; MOURA, A. D.; LOBO, S. M.; AZEVEDO, L. C. P.; MACHADO, F. R. Differences in Sepsis Treatment and Outcomes between Public and Private Hospitals in Brazil: A Multicenter Observational Study. PLoS ONE, v. 8, n. 6, p. e64790, 6 jun. 2013.

CRUZ-MACHADO, S. da S. Lipopolissacarídeo (LPS): ativador e regulador da transcrição gênica via fator de transcrição NFKB. Revista da Biologia, v. 4, p. 40-43, 2010.

EMÍlIO-SILVA, M. T.; MOTA, C. M. D.; HIRUMA-LIMA, C. A.; ANTUNESRODRIGUES, J.; CÁRNIO, E. C.; BRANCO, L. G. S. Antipyretic Effects of Citral and Possible Mechanisms of Action. Inflammation, v. 40, n. 5, p. 1735-1741, 2017.

FERNÁNDEZ, R. A. R.; SORIANO, R. N.; FRANCESCATO, H. D. C.; SABINO, J. P.; COIMBRA, T. M.; BRANCO, L. G. S. Cryogenic role of central endogenous hydrogen sulfide in the rat model of endotoxic shock. Brain Research, v. 1650, p. 218-223, 2016.

FINK, M. P.; WARREN, H. S. Strategies to improve drug development for sepsis. Nature Reviews Drug Discovery, v. 13, n. 10, p. 741-758, 5 out. 2014.

FLEISCHMANN, C.; SCHERAG, A.; ADHIKARI, N. K. J.; HARTOG, C. S.; TSAGANOS, T.; SCHLATTMANN, P.; ANGUS, D. C.; REINHART, K. Assessment of Global Incidence and Mortality of Hospital-treated Sepsis. Current Estimates and Limitations. American Journal of Respiratory and Critical Care Medicine, v. 193, n. 3, p. 259-272, 1 fev. 2016.

FRACASSO, J. F. Contribuição ao entendimento da patogenia da sepse. Revista de Ciencias Farmaceuticas Basica e Aplicada, v. 29, n. 2, p. 119-127, 2008.

GEROULANOS, S.; DOUKA, E. T. Historical perspective of the word "sepsis". Intensive Care Medicine, v. 32, n. 12, p. 2077-2077, 27 nov. 2006.

GIUSTI-PAIVA, A.; DE CASTRO, M.; ANTUNES-RODRIGUES, J.; CARNIO, E. C. Inducible nitric oxide synthase pathway in the central nervous system and vasopressin release during experimental septic shock. Critical care medicine, v. 30, n. 6, p. 1306-1310, 2002.

KAPUR, A.; FELDER, M.; FASS, L.; KAUR, J.; CZARNECKI, A.; RATHI, K.; ZENG, S.; OSOWSKI, K. K.; HOWELL, C.; XIONG, M. P.; WHELAN, R. J.; PATANKAR, M. S. 
Modulation of oxidative stress and subsequent induction of apoptosis and endoplasmic reticulum stress allows citral to decrease cancer cell proliferation. Scientific Reports, v. 6, n. Mai, p. 1-14, 2016.

KARIMA, R.; MATSUMOTO, S.; HIGASHI, H.; MATSUSHIMA, K. The molecular pathogenesis of endotoxic shock and organ failure. Molecular medicine today, v. 5, n. 3, p. 123-32, mar. 1999.

KATSUKAWA, M.; NAKATA, R.; TAKIZAWA, Y.; HORI, K.; TAKAHASHI, S.; INOUE, H. Citral, a component of lemongrass oil, activates PPAR $\alpha$ and $\gamma$ and suppresses COX-2 expression. Biochimica et Biophysica Acta (BBA) - Molecular and Cell Biology of Lipids, v. 1801, n. 11, p. 1214-1220, nov. 2010.

KI, T.; HADE, T. S.; MAMAI, U. W. E.; NTER, G.; BRADE, H.; LOEPNO, H.; PAVA, F. O. D. I. Bacterial endotoxin : molecular relationships of structure to activity and function. The FASEB Journal, v. 8, n. 2, p. 217-225, 1994.

KRALL, C. M.; YAO, X.; HASS, M. a; FELEDER, C.; STEINER, A. a. Food deprivation alters thermoregulatory responses to lipopolysaccharide by enhancing cryogenic inflammatory signaling via prostaglandin D2. American journal of physiology. Regulatory, integrative and comparative physiology, v. 298, n. 6, p. R1512-21, 2010.

KWIATKOSKI, M.; SORIANO, R. N.; ARAUJO, R. M.; AZEVEDO, L. U.; BATALHAO, M. E.; FRANCESCATO, H. D. C.; COIMBRA, T. M.; CARNIO, E. C.; BRANCO, L. G. S. Hydrogen sulfide inhibits preoptic prostaglandin E2 production during endotoxemia. Experimental Neurology, v. 240, n. 1, p. 88-95, 2013.

LAZARUS, M. The differential role of prostaglandin E2 receptors EP3 and EP4 in regulation of fever. Molecular Nutrition \& Food Research, v. 50, n. 4-5, p. 451-455, abr. 2006.

LEE, H. J.; JEONG, H. S.; KIM, D. J.; NOH, Y. H.; YUK, D. Y.; HONG, J. T. Inhibitory effect of citral on NO production by suppression of iNOS expression and NF- $\mathrm{KB}$ activation in RAW264.7 cells. Archives of Pharmacal Research, v. 31, n. 3, p. 342-349, 13 mar. 2008.

MACHADO, F. R. et al. The epidemiology of sepsis in Brazilian intensive care units (the Sepsis PREvalence Assessment Database, SPREAD): an observational study. The Lancet 
Infectious Diseases, v. 17, n. 11, p. 1180-1189, 1 nov. 2017.

MOGENSEN, T. H. Pathogen recognition and inflammatory signaling in innate immune defenses. Clinical Microbiology Reviews, v. 22, n. 2, p. 240-273, 2009.

NEMZEK, J. A.; HUGUNIN, K. M. S.; OPP, M. R. Modeling sepsis in the laboratory: Merging sound science with animal well-being. Comparative Medicine, v. 58, n. 2, p. 120$128,2008$.

NISHIJIMA, C. M.; GANEV, E. G.; MAZZARDO-MARTINS, L.; MARTINS, D. F.; ROCHA, L. R. M.; SANTOS, A. R. S.; HIRUMA-LIMA, C. A. Citral: A monoterpene with prophylactic and therapeutic anti-nociceptive effects in experimental models of acute and chronic pain. European Journal of Pharmacology, v. 736, p. 16-25, 5 ago. 2014b.

OGNIBENE, F. P.; PARKER, M. M.; NATANSON, C.; SHELHAMER, J. H.; PARRILLO, J. E. Depressed left ventricular performance. Response to volume infusion in patients with sepsis and septic shock. Chest, v. 93, n. 5, p. 903-10, maio 1988.

OKA, T. Prostaglandin E2 as a mediator of fever: the role of prostaglandin E (EP) receptors. Frontiers in bioscience : a journal and virtual library, v. 9, p. 3046-57, 1 set. 2004.

PŁÓCIENNIKOWSKA, A.; HROMADA-JUDYCKA, A.; BORZĘCKA, K.; KWIATKOWSKA, K. Co-operation of TLR4 and raft proteins in LPS-induced proinflammatory signaling. Cellular and Molecular Life Sciences, v. 72, n. 3, p. 557-581, 22 fev. 2015.

PRADO, A. Poesia Reunida. 1. ed. São Paulo: Siciliano, 1991.

ROMANOVSKY, A. A.; IVANOV, A. I.; SHIMANSKY, Y. P. Selected Contribution: Ambient temperature for experiments in rats: a new method for determining the zone of thermal neutrality. Journal of Applied Physiology, v. 92, n. 6, p. 2667-2679, jun. 2002.

RUDAYA, A. Y.; STEINER, A. A.; ROBBINS, J. R.; DRAGIC, A. S.; ROMANOVSKY, A. A. Thermoregulatory responses to lipopolysaccharide in the mouse: dependence on the dose and ambient temperature. American Journal of Physiology-Regulatory, Integrative and Comparative Physiology, v. 289, n. 5, p. R1244-R1252, nov. 2005. 
SAIA, R. S.; BERTOZI, G.; MESTRINER, F. L.; ANTUNES-RODRIGUES, J.; QUEIRÓZ CUNHA, F.; CÁRNIO, E. C. Cardiovascular and inflammatory response to cholecystokinin during endotoxemic shock. Shock, v. 39, n. 1, p. 104-112, 2013.

SAPER, C. B.; ROMANOVSKY, A. A.; SCAMMELL, T. E. Neural circuitry engaged by prostaglandins during the sickness syndrome. Nature Neuroscience, v. 15, n. 8, p. 10881095, 2012.

SINGER, M., et al.; BELlOMO, R.; BERNARD, G. R.; CHICHE, J.; CRAIG, M.; HOTCHKISS, R. S.; LEVY, M. M.; MARSHALL, J. C.; MARTIN, G. S.; OPAL, S. M.; RUBENFELD, G. D.; DER, T. Van; VINCENT, J.; ANGUS, D. C. HHS Public Access. Jama, v. 315, n. 8, p. 801-810, 2016.

SONG, Y.; ZHAO, H.; LIU, J.; FANG, C.; MIAO, R. Effects of Citral on Lipopolysaccharide-Induced Inflammation in Human Umbilical Vein Endothelial Cells. Inflammation, v. 39, n. 2, p. 663-671, 2016.

TITHERADGE, M. Nitric oxide in septic shock. Biochimica et biophysica acta, v. 1411, p. 437-455, 1999.

UENO, R.; NARUMIYA, S.; OGOROCHI, T.; NAKAYAMA, T.; ISHIKAWA, Y.; HAYAISHI, O. Role of prostaglandin D2 in the hypothermia of rats caused by bacterial lipopolysaccharide. Proceedings of the National Academy of Sciences of the United States of America, v. 79, n. 19, p. 6093-7, out. 1982.

ULEVITCH, R. J.; TOBIAS, P. S. Receptor-dependent mechanisms of cell stimulation by bacterial endotoxin. 1995. Annual review immunology, v. 13, p. 437-457, 1995.

VAN DER POLL, T.; VAN DE VEERDONK, F. L.; SCICLUNA, B. P.; NETEA, M. G. The immunopathology of sepsis and potential therapeutic targets. Nature Reviews Immunology, v. 17, n. 7, p. 407-420, 2017.

WESTPHAL, O.; LUDERITZ, O.; RIETSCHEL, E. T.; GALANOS, C. Bacterial lipopolysaccharide and its lipid A component: some historical and some current aspects. Biochem Soc Trans, v. 9, n. 3, p. 191-195, 1981. 